\title{
The Role of micro RNAs in Breast Cancer Metastasis: Preclinical Validation and Potential Therapeutic Targets
}

\author{
ULRICH H. WEIDLE ${ }^{1}$, STEFFEN DICKOPF ${ }^{2}$, CORINNA HINTERMAIR ${ }^{3}$, \\ GWENDLYN KOLLMORGEN $^{1}$, FABIAN BIRZELE $^{4}$ and ULRICH BRINKMANN ${ }^{2}$ \\ ${ }^{1}$ Roche Pharma Research and Early Development, Roche Innovation Center Munich, Penzberg, Germany; \\ ${ }^{2}$ Roche Pharma Research and Early Development, Large Molecule Research, \\ Roche Innovation Center Munich, Penzberg, Germany; \\ ${ }^{3}$ Helmholtz Zentrum, Molecular Epigenetics, Munich, Germany; \\ ${ }^{4}$ Roche Pharma Research and Early Development, Pharmaceutical Sciences, \\ Roche Innovation Center Basel, Basel, Switzerland
}

\begin{abstract}
Despite the approval of several molecular therapies in the last years, breast cancer-associated death ranks as the second highest in women. This is due to metastatic disease, which represents a challenge for treatment. A better understanding of the molecular mechanisms of metastasis is, therefore, of paramount importance. In this review we summarize the role of micro RNAs (miRs) involved in metastasis of breast cancer. We present an overview on metastasis-promoting, -suppressing and context-dependent miRs with both activities. We have categorized the corresponding miRs according to their target classes, interaction with stromal cells or exosomes. The pathways affected by individual miRs are outlined in regard to in vitro properties, activity in metastasis-related in vivo models and clinical significance. Current approaches that may be suitable for therapeutic inhibition or restauration of miR activity are outlined. Finally, we discuss the delivery bottlenecks which present as a major challenge in nucleic acid (miR)-based therapies.
\end{abstract}

This article is freely accessible online.

Correspondence to: Ulrich Brinkmann, Roche Innovation Center Munich, 82377 Penzberg, Germany. Tel: +49 8856604753, e-mail: ulrich.brinkmann@roche.com; or to Ulrich H. Weidle, Roche Pharma Research and Early Development, Roche Innovation Center Munich, Germany. Tel: +49 15114096083, e-mail: weidle49@tonline.de

Key Words: Colonization of distinct organs, epithelial-mesenchymal transition (EMT), exosomes, metastasis-related in vivo models, mesenchymal-epithelial transition (MET), migration and invasion, tumor cell/stromal cell interactions, review.
Breast Cancer (BC) is the second leading cause of death in women with a death toll of 40,000 in the US in 2015 (1). In recent years there have been a number of advances in targeted therapies for $\mathrm{BC}$, for example the combination of aromatase inhibitors with everolimus (afinitor) and cyclindependent kinases 4/6 (cdk4/6) inhibitors such as palbociclib (ibrance) in estrogen-receptor-positive $\left(\mathrm{ER}^{+}\right)$tumors, the use of trastuzumab (herceptin), pertuzumab (perjeta) and adotrastuzumab emtansine (kadcyla) in patients with human epidermal growth factor 2 overexpressing (HER2 ${ }^{+}$) tumors and the identification of subgroups of BC patients which respond to Platin-based chemotherapy and poly (adenosinediphosphate-ribose polymerase) (PARP) inhibitors (2)). Yet despite these improvements, a high death toll remains and is due to the difficult tractability of metastatic disease, which is only poorly affected by these agents. A further complicating issue is the fact that the frequency of mutated drivers such as ER, HER2, phosphatidylinositol 3-kinase catalytic $\alpha$ polypeptide (PIK3CA) and AKR mouse thyoma kinase 1 (AKT1) is low in BC metastases (3). Another critical issue is the heterogeneity of the disease as manifested by the occurence of several histological and molecular subtypes (4). Whereas targeting the seeds of metastasis is difficult, progress has been made by targeting the soil in prevention and treatment of $\mathrm{BC}$-derived bone metastasis. Treatment with bisphosphonates, receptor activator of nuclear factor $\mathrm{kB}$ (RANK)-monoclonal antibody denosumab and transforming growth factor $\beta$ (TGF $\beta$ ) inhibitors such as LY157299 inhibit osteoclasts, which contribute to the pathogenesis of metastatic colonization (5).

The invasion-metastasis cascade is defined by distinct steps such as invasion, intravasation, survival in the circulation, arrest at distant organ sites, formation of 
micrometastases and metastatic colonization $(6,7)$. Several promising targets for inhibition of BC metastases have been identified, but their clinical validation is still pending $(6,7)$. One has to keep in mind that BC can disseminate to different organs such as the bones, lungs and brain, making use of organ-tropism specific mechanisms. In addition to these pathways, shared mechanisms seem to be activated in metastatic BC (8).

In this review we focus on the role of micro RNAs (miRs) as modulators of BC metastasis. As promoters or suppressors, such miRs may also serve as targets for therapeutic intervention.

\section{miRs - General Aspects and Roles in Cancer}

MiRs are small non-coding RNAs with lengths varying between 18 and 25 nucleotides (nts). In contrast to longnoncoding RNAs they are evolutionary conserved $(9,10)$ and involved in post-transcriptional regulation of gene expression. Their molecular mode of action is targeting specific mRNAs via complementary sequences resulting in their degradation by RNAses or inhibition of translation (11). More than $1000 \mathrm{miR}$ genes have been identified in the human genome, the vast majority of them being transcribed by RNA polymerase II. This generates primary transcripts referred to as pri-miRNA which contain a 7-methyl-guanosin cap, a polyA-tail and may additionally contain introns (12, 13). Pri-miRs can be transcribed from intergenic regions or from introns and can encode a single miR or clusters of two or more miRs (13). The pre-miRs are cleaved by the Microprocessor complex which is composed of DROSHA, a double-stranded RNAse III enzyme and its co-factor doublestranded RNA binding DiGeorge syndrome critical region 8 (DGCR8) (14). Each strand of the doubled-stranded pri-miR is cleaved, resulting in the generation of a hairpin shaped precursor miR (pre-miRNA) comprised of 60-70 nts. This precursor is exported by double-stranded RNA binding protein exportin 5 (XPO5) (15) to the cytoplasm. MiRs with mRA degradation functionality interact in the cytoplasm with the RNAse DICER and finally form the RNA-induced silencing complex (RISC) (16). The latter consists of the transactivation-responsive RNA binding protein (TRBP) and Argonaute 2 (Ago2) which together with DICER give rise to a mature miR-miR* 18-25 nts duplex. Finally, the two strands are separated: the mature miR strand (guide strand) is incorporated into the RISC, whereas the passenger miR* strand can be loaded into the RISC or be degraded. A 6-8 nts sequence at the 5'end of the miR is crucial for mRNA target selection, preferentially located in the 3'-untranslated region (3'-UTR) of the target mRNA $(17,18)$. After base pairing, potential functional consequences are degradation of the corresponding mRNA or inhibition of its translation. Overall, one should keep in mind that a miR can target several different mRNAs and individual mRNAs can be suppressed by multiple miRs, underlining the important role of miRs in gene regulatory networks. It is expected that the functional outcome of inhibition or activation of a specific miR will be context-dependent based on the transcriptional program of an individual cell. It is expected that $30-50 \%$ of human genes are post-transcriptionally regulated by miRs $(9,11)$.

An important impact of miRs covering all stages of pathogenesis has been noted in cancer $(9,19,20)$. Oncogenic and tumor-suppressive functions or in some cases both roles have been assigned to defined miRs $(18,21)$. These findings rely on proof-of-concept experiments in B-cell chronic lymphocytic leukemia (B-CLL) (22). Tumor suppressors frequently deleted in B-CLL were identified on chromosome 13q14, a locus containing two miR genes, miR15a and miR16-1 (22). Their function could be delineated to repression of B-cell lymphoma 2 (Bcl-2), an anti-apoptotic protein overexpressed in B-CLL and many types of solid tumors (23, 24). Noteworthy, deletion of the miR-15 and miR-16-1 cluster in mice recapitulated the human disease phenotype of B-CLL (25).

In this review we specifically focus on the role of miRs in metastasis of BC. We discuss metastasis-promoting and metastasis-suppressing miRs as well as miRs with contextdependent metastasis-related function in BC. For interpretation of the results presented it should be considered that BC molecular subtypes can be defined based on their transcriptional profile which might be responsible for subtype specific function of defined miRs. The major subtypes identified are: luminal A (ER high, HER2 low), prevalence $40 \%$; luminal B (ER low, HER2 low), prevalence 20\%; HER2-enriched (HER2 high, ER ${ }^{-}$), prevalence 10-15\%; basal-like, triple-negative breast cancer (ER-, progesterone receptor negative $\left.\left(\mathrm{PR}^{-}\right), \mathrm{HER} 2^{-}\right)$, prevalence $10-15 \%$ and claudin-low (claudin 3,4,7 low, E-cadherin low, vimentin+ and zinc finger E-box-binding homeobox 1 (zeb1)+), prevalence $12-14 \%(26,27)$. Different breast cancer-derived cell lines represent and serve as in vitro models for different subtypes of BC. These will therefore also be adressed when discussing the role of specific miRs in metastasis (27).

\section{Breast Cancer Metastasis-promoting miRs}

In this chapter we are alluding to miRs with validated mode of action in vitro and in vivo with respect to metastasisrelated functions and documented correlation to clinical features of metastatic BC. Metastasis-promoting miRs can be expressed by tumor cells, or they can be activated by interaction between stromal cells and tumor cells and prometastatic miRs transferred by exosomes. In the first paragraphs we summarize miRs expressed by tumor cells which down-regulate metastasis-suppressing genes, RhoROCK signaling related miRs and miRs with an impact on a variety of other signaling pathways. 
miRs targeting metastasis-suppressing genes.

$m i R-21:$ miR-21 is a BC-related target with an impact on tumorigenesis as well as metastasis. The tumorigenesisrelated proteins tumor suppressor phosphatase and tensin homolog (PTEN) (28) and anti-apoptotic protein bcl-2 have been identified as targets (29). Here we focus on the metastasis-related functions of miR-21. The following have been identified as anti-invasive targets of miR-21: metastasis-suppressors programmed cell death 4 (PDCD4) $(30,31)$, maspin $(30,32)$, tumor suppressor gene tropomyosin $(30,33,34)$ and tissue inhibitor of metalloproteinase 3 (35). Interestingly, HER2-induced motility of BC cells is mediated by E26 transformation specific-1 (Ets-1) induced miR-21 transcription and inhibition of its downstream effector PDCD4 (36). Suppression of miR-21 in MDA-MB-231 (basal-type BC cells) is associated with a 10 -fold decrease of invasion in vitro and lung metastasis after tail vein injection (30). Regarding the relevance of miR-21 as a prognostic parameter, it has been shown that miR-21 overexpression in human $\mathrm{BC}$ is associated with clinical stage, lymph node metastasis and patient poor prognosis (37).

miR-93: miR-93 was identified as a miR up-regulated in BC specimens in comparison to benign breast tissue (38). MT-1 BC cells (human, ER-, PR-, HER2+) transfected with miR-93 gave rise to tumors with increased density of blood vessels in non-obese diabetic-severe combined immunodeficiency (NOD-SCID) mice and enhanced lung metastasis after tail vein injection (38). Large tumor suppressor, homology 2 (LATS2) was identified as a direct target of miR-93 (38-41). Ectopic expression of LATS2 decreased survival and invasion of MT-1 cells (38). Moreover, when miR-93 is overexpressed in the marginally invasive MCF-7 cells, proliferation and invasion of these cells is increased (42). In situ-hybridization of miR-93 in BC tissues indicated elevated expression levels especially in triple negative breast cancer (TNBC) pointing to a possible role of miR-93 as a biomarker in this subtype of BC (42).

\footnotetext{
Metastasis-promoting miRs targeting the Rho-ROCK signaling pathway. Rho-associated kinases (ROCKs) regulate morphology, adhesion, stress fiber formation and motility through their serine-threonine kinase activity $(43,44)$. ROCK signaling has been implicated with BC metastasis and ROCK expression in late stage tumors and metastases is negatively correlated with survival (43).

miR-10b: miR-10b was identified as a miR up-regulated in several metastatic BC cells and is located in the intergenic region between homeobox domain 4 (HOXD4) and HOXD8 genes $(45,46)$. miR-10b is induced by the epithelial mesenchymal transition (EMT)-promoting transcription factor Twist and inhibits translation of the transcriptional repressor HOXD10 (45). As a consequence, tumor-spreading promoting
}

targets such as GTPase RhoC, urokinase plasminogen activator receptor (UPAR) and matrix metalloprotease 14 (MMP-14) are overexpressed (45). Independently, syndecan, functioning as a transmembrane co-receptor for growth factors, chemokines and angiogenic factors as well as a matrix adhesion receptor (47, 48) was identified as a target of miR-10a. Ectopic expression of miR-10b in immortalized human mammary epithelial cells (HMEC) and non-metastatic SUM149 BC cells (basal subtype) (49) had no effect on proliferation in vitro, but mediated a 4-6 fold increase in cell motility and invasiveness (45). Ectopic expression of miR-10b in the non-invasive SUM149 cells and in the invasive, but non-metastatic SUM159 BC cells (basal subtype) (49), had no impact on tumor growth after fat pad implantation, but mediated appearance of lung metastases and macroscopic peritoneal metastases (45). Therapeutic proof-ofconcept (POC) experiments were performed in the syngeneic 4T1 mouse BC model (subtype TNBC) based on a transplantable cell line which produces metastatic tumors in lung, liver, lymph nodes and brain (50). In this model dissemination of fat pad implanted 4T1 cells to the lungs was suppressed after systemic administration of anti-miR-10b antagomirs, chemically modified anti-miR oligonucleotides (51). Similar results were obtained by expression of a miR-10b sponge containing multiple 3'UTR tandem binding sites for miR-10b, in 4T1 cells. Interestingly, the miR-10b antagomir did not affect lung colonization of 4T1 cells after tail vein injection, pointing to a role of miR-10b in earlier stages of the metastatic process in this system (51). Regarding clinical correlation, the expression of miR-10b was lower in breast carcinomas from metastasis-free patients $(n=5)$ and $50 \%$ of metastasis-positive patients $(9 / 18)$ had elevated miR-10b levels in their primary tumors (45).

$m i R-548 \mathrm{j}$ : miR-548j was identified in a genetic screen by transducing a lenti-miR virus library into MCF-7 (BC subtype luminal A) cells followed by transwell invasion assays (52). Endogenous levels of miR-548j in BC cells correlate with invasiveness and miR-548j overexpression stimulates BC cell invasion in vitro in MCF-7, SKBr3 and MDA-MB-231 BC cells. MDA-MB-231 cells transfected with a miR-548j mimic metastasize to the lungs after tail vein injection, without affecting proliferation (52). Tensin-1, a protein which localizes to focal adhesions and is involved in cell migration (53) was identified as a direct target for miR-548j (52). miR$548 \mathrm{j}$ mediated inhibition of tensin-1 relieves inhibition of cell division cycle protein 42 homolog (cdc42), a small GTPase of the ras homologue (Rho) family which is involved in control of pathways mediating morphology, migration, endocytosis, cell-cycle progression and invasion (54). Migration of BC cells as outlined above could be inhibited by ML141, a small molecule cdc42 inhibitor (52). Using two sets of clinical samples, a strong correlation between the expression level of miR-548j and lymph node metastasis and survival has been observed in BC patients (52). 
miRs-125b, -182 and -1792: For miR-125b, StAR-related lipid transfer domain protein 13 (STARD13) (55-57) has been identified as a target. STARD13 inhibits RhoA activity and thus activates ROCK signaling resulting in up-regulation of the EMT markers vimentin and $\alpha$ smooth muscle actin and reorganization of the cytoskeleton. miR-125b mimics induce migration in MCF7 and MDA-MB-231 cells (claudin-low subtype). MCF-7 cells with up-regulated expression of miR-125b give rise to metastases in the kidney, lungs and eyes after injection into the lateral vein (55). A clinical correlation between expression of miR-125b and BC metastasis has not yet been worked out. miR-182 targets Missing in Metastasis (MIM) $(58,59)$ resulting in activation of RhoA and stress fiber formation (60). Ectopic expression of miR-182 enhances BC cell mobility and invasion and increases pulmonary colonization of BC cells (60). In BC specimens, miR-182 induction is linked to down-regulation of MIM, RhoA activation and poor prognosis (60).

miR-1792 is a downstream effector of ROCK signaling. ROCK expression $(43,44)$ is enhanced in metastatic human $\mathrm{BC}$ and $\mathrm{BC}$ cell lines in comparison to non-metastatic BC cell lines (60). Overexpression of ROCK mediates cell migration and proliferation of non-metastatic MCF-7 cells and their metastasis to the bones (60). Concomittantly miR-1792 is induced and its expression is diminished by treatment with ROCK inhibitor Y27632 (60). miR-1792 is overexpressed in metastatic BC and is involved in proliferation and motility of BC cells (60). Intratumorally injected anti-miR-1792 agents do not affect the growth of primary MDA-MB-231 cells, but the frequency of metastasis to the bones was reduced by $50 \%$ compared to a scrambled control (60). The role of miR-1792 as a downstream effector of ROCK signaling and other not yet identified pathways in BC metastasis warrants further investigations. Figure 1 displays the MOA of BC-metastasis promoting miRs-10b, $-126,-182,-1792$ and $-5485 \mathrm{j}$, which all promote activation of ROCK.

miRs interfering with other signaling pathways. miR-9: miR9 was identified by screening mammary carcinoma cells for up-regulated miRs through real-time RT-PCR (61). miR-9 expression is up-regulated by MYC and N-MYC. E-cadherin has been identified as one of the crucial targets of miR-9. Ecadherin associates with intracellular proteins that link Ecadherin to the actin cytoskeleton and its down-regulation dissociates carcinoma cells from each other $(62,63)$. In addition, loss of E-cadherin leads to movement of $\beta$-catenin into the nucleus to activate pro-metastatic genes (64). Vascular endothelial growth factor (VEGF) has been identified as one of the target genes of $\beta$-catenin in SUM149 cells in vitro and in vivo, resulting in a 10-fold increase of the density of intratumoral microvessels (61). Ectopic expression of miR-9 in immortalized human mammary luminal epithelial cells (HMLE) results in EMT-like conversion, but not in SUM 149 cells (basal subtype), pointing to a context-dependent phenomenon (61). Ectopic expression of miR-9 in SUM149 cells mediated the establishment of lung metastases after fat pad implantation, in contrast to the non-transfected cells (61). In the previously described 4T1 mammary carcinoma model, expression of a miR-9 sponge in 4T1 cells reduced the number of lung metastases by $50 \%$ after fat pad implantation in immunocompetent Balb/c mice (61). A clinical correlation of miR-9 expression and prognosis in BC patients revealed elevated expression of miR-9 in primary breast tumors with diagnosed metastases compared to those from metastasis-free patients (61). Earlier reports (65) indicated up-regulation of miR-9 in clinical breast cancers.

miR-24: miR-24 was identified as a miR with increased expression in $\mathrm{BC}$ tissue compared to benign breast tissue (66). Ectopic expression promotes invasion and migration of the BC cells 4T1 and MT-1 (66). miR-24 transfected MT-1 cells promote increased tumor growth and formation of lung metastases after tail vein injection (66). Protein tyrosine phosphatase non-receptor 9 (PTPN9) and protein tyrosine phosphatase receptor $\mathrm{F}$ (PTPRF) $(67,68)$ have been identifed as direct targets of miR-24 (66) resulting in up-regulation of phosphorylated epidermal growth factor receptor ( $\mathrm{pEGFR}$ ). miR-24 promotes the increased expression of downstream effectors such as MMP-2, MMP-11 and a disintegrin and metalloprotease 15 (ADAM15), mediators of cell invasion, migration and metastasis (66). pEGFR was found to be more abundant in BC tissues than in normal breast tissue and immuno-histochemistry (IHC) revealed that PTPN9 and PTPRF gave rise to much weaker signals in tumor tissues than in normal breast tissue (66). Studies addressing the inverse relationship between expression of PTPN9, PTPRF and $\mathrm{pEGFR}$ in $\mathrm{BC}$ versus normal breast tissue have to be extended to more patients.

miR-181a: Late-stage $\mathrm{BC}$ metastasis is driven by dysregulated transforming growth factor $\beta$ (TGF $\beta$ ) signaling (69). In 3D organotypic cultures, miR-181a is up-regulated by TGF $\beta$ and inactivation of miR-181a attenuates TGF $\beta$ mediated EMT, invasion and migration (70). Pro-apoptotic protein Bim was identified as one of the targets of miR-181a, resulting in decrease of anoikis after inhibition by miR-181a (71). Inactivation of miR-181a in 4T1 cells impaired their ability to grow as 3D organotypic cultures (70). In an experimental metastasis model, inhibition of miR-181a in 4T1 cells decreased pulmonary tumor burden and increased survival time (70). In an orthotopic fat pad injection-based metastasis model, miR-181a was essential for pulmonary metastatic outgrowth of 4T1 cells (70). Regarding clinical prognostic relevance, miR-181a was shown to be selectively up-regulated in metastatic BC, particularly in TNBC and upregulation was highly predictive for overall survival in $\mathrm{BC}$ 


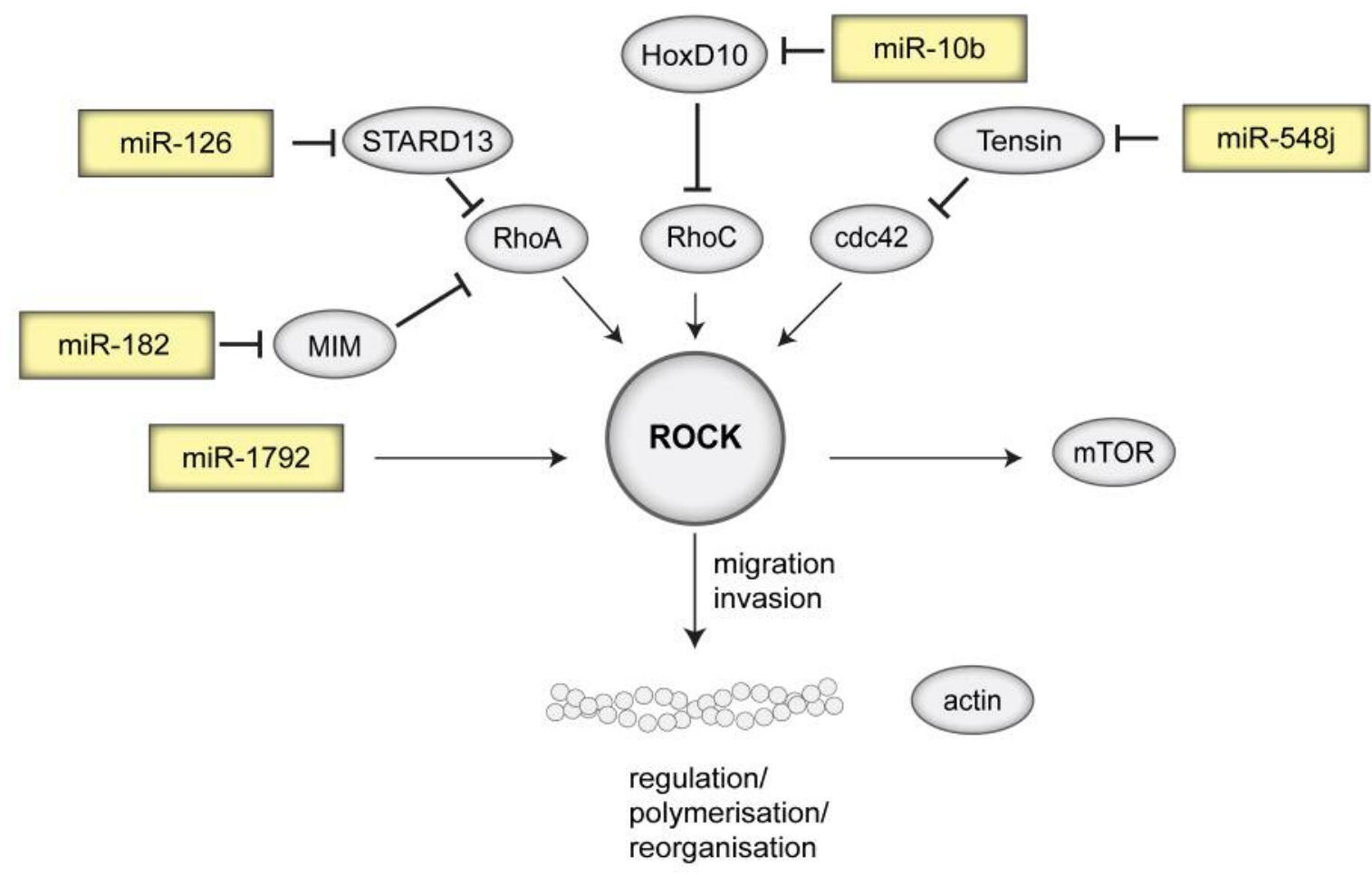

Figure 1. miRs promoting breast cancer metastasis by activation of ROCK signaling. miRs 10b, -126, -182, -548j and -1792 activate several small GTPases resulting in activation of ROCK signaling followed by modification of actin and migration and invasion of breast cancer cells. Cdc 42: Cell division cycle protein 42; HoxD10: homeobox domain 10; MIM: missing in metastasis; mTOR: mechanistic target of rapamycin; RhoA: ras homologue A; Rho C: ras homologue C; ROCK: Rho-associated kinase; STARD13: StAR-related lipid transfer domain protein 13.

patients (70). Figure 2 shows the MOA of BC-metastasis promoting miRs $-9,-21,-24,-93$ and -181 .

miRs-199a and -494 involved in interactions between tumor cells and stromal cells. miR199a: The interaction between mesenchymal stem/stromal cells (MSC) and BC cells is an important driver of $\mathrm{BC}$ metastasis $(72,73)$. Recently, involvement of miR-199a primed in BC cells after interaction with MSC was reported to play an important role in this process (74). MDA-MB-231 cells transfected with miR-199a exhibit increased cancer stem cell (CSC)-related traits such as tumor-initiating capabilities in mice, improved capability to grow as mammospheres and elevated expression of CSC marker aldehyde dehydrogenase 1 (ALDH1) (74). From a mechanistic point of view, downregulation of speech gene, transcription factor forkhead box P2 (FoxP2) $(74,75)$, a common target of a converging set of MSC-regulated miRs was identified as a target of miR199a (74). Down-regulation of FoxP2 results in tumor-initiating properties and metastasis. Although elevated miR-199a and depleted FOXP2 have been found in clinical BC specimens, this needs to be further investigated before a clinical impact can be determined (74).
miR-494: miR-494 was identified as a BC-metastasis mediating miR expressed in myeloid-derived suppressor cells (MDSC) after induction by tumor-derived TGF $\beta$ (76). miR494 targets PTEN and thereby activates the Akt pathway (76). Akt mediates mechanistic target of rapamycin (mTOR) and nuclear factor $\mathrm{kB}(\mathrm{NFKB})$ signaling, which leads to the expression of MMPs by MDSCs and promotes metastases of $\mathrm{BC}$ cells. In addition, enhanced expression of $\mathrm{C}-\mathrm{X}-\mathrm{C}$ chemokine receptor 4 (CXCR4) on MDSCs mediated chemotaxis and subsequent accumulation of MDSCs in tumors (76-78). miR-494 is highly expressed in tumor-expanded MDSCs and knock-down of miR-494 by a lentivirus-based sponge attenuates primary tumor growth and metastasis of 4T1 cells (76). Data regarding clinical significance of these findings with respect to $\mathrm{BC}$ metastasis are not yet available.

miRs transferred by exosomes: miR-19a, -105, -122 and 223. miR-19a: miR19a is transferred via exosomes from astrocytes to mouse (4T1) and human (HCC 1954, BT474, MDA-MB-231) BC cells and mediates adaptive loss of tumor suppressor PTEN in brain metastatic tumor cells (79). Blockage of astrocyte exosome secretion rescues PTEN loss and suppresses metastasis of a subclone of MDA-MB-231 


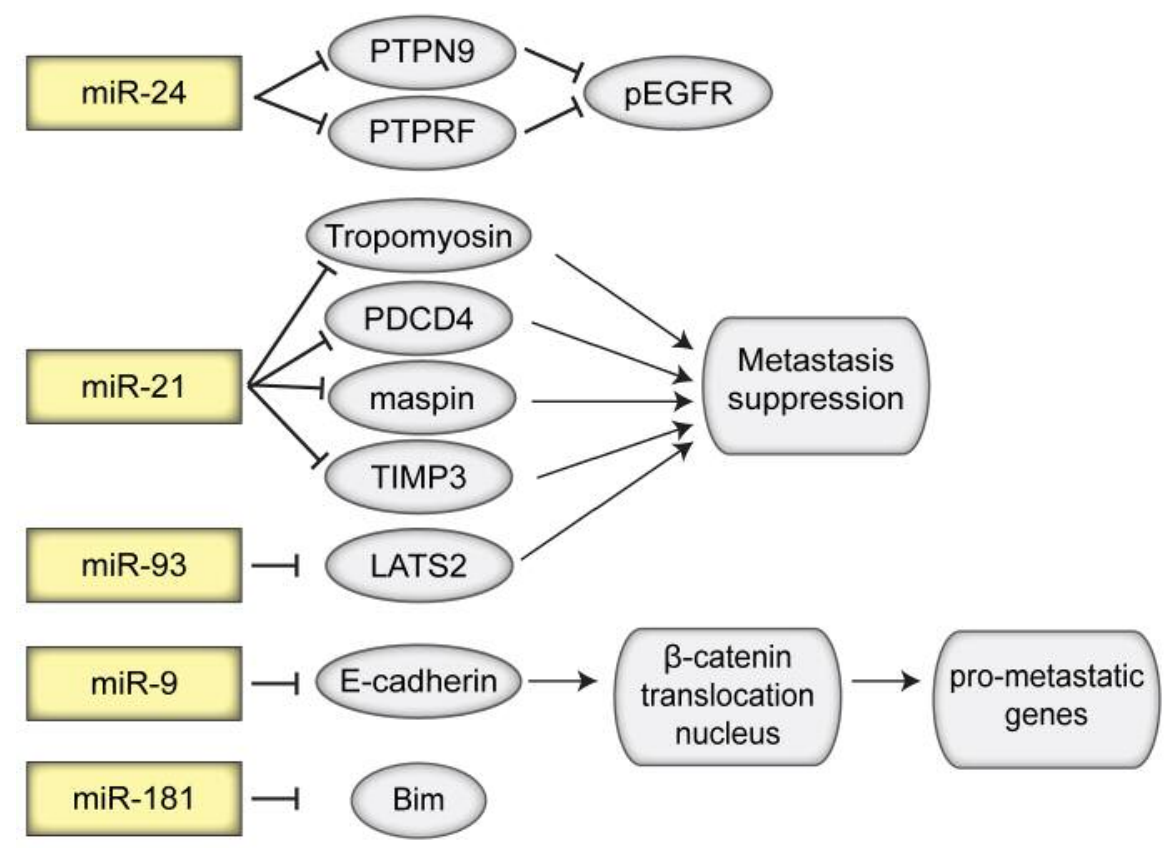

Figure 2. Mode of action of selected BC-promoting miRs. The left-hand panel displays selcted miRs. The corresponding targets are shown in the middle panel and the physiological consequences of target inhibition are shown in the right-hand panel. LATS2: Large tumor suppressor, homology 2; PDCD4: programmed cell death 4; pEGFR: phosphorylated epidermal growth factor receptor; PTPN9: tyrosine-protein phosphatase non-receptor 9; PTPRF: receptor tyrosine phosphatase $F$.

cells with high tropism of metastasis to the brain (79). Elimination of PTEN is brain-specific and does not occur in $\mathrm{BC}$ cells disseminating to other organs. Loss of PTEN in BC cells leads to increased secretion of CC-chemokine ligand 2 (CCL2) (79-82), a recruiter of IBA-1-expressing myeloid cells which enhance outgrowth of metastatic tumor cells in the brain via enhanced proliferation and reduced apoptosis. IHC staining of human primary BC and brain metastases indicated higher CCL2 expression in brain metastases than in primary tumors (79). These findings suggest CCL2 targeting for therapeutic intervention of life-threatening BCderived brain metastases.

miR-105: miR-105 is expressed by metastatic BC cells and can also be transferred by exosomes (83). In vitro, exosomes harbouring miR-105 have been shown to target endothelial monolayers by inhibition of tight junction protein zonula occludens-1 protein (ZO-1) $(83,84)$. Pre-treatment of mice with exosomes exhibiting high levels of miR-105 derived from MDA-MB-231 cells, but not those derived from MCF-7 cells, mediated metastasis of MDA-MB-231 cells to the lungs and the brain after intracardiac injection (83). High vascular permeability and reduced levels of ZO-1 were observed in MCFDCIS (a tumorigenic cell line derived from the non-cancerous mammary epithelial MCF10A cell line) orthotopic xenografts overexpressing miR-105 (83). In patients who later developed distant metastases higher levels of tumor miR-105 and lower levels of tumor and vascular ZO-1 were observed (83). miR-105 has potential as a blood-based marker for prediction or early diagnosis of BC metastases (83).

miR-122: miR-122 has been identified as a miR with the capability to reprogram glucose metabolism in the premetastatic niche to promote metastasis (85). miR-122 is secreted in vesicles by $\mathrm{BC}$ cells and down-regulates the glycolytic enzyme pyruvate kinase $\mathrm{M}$ (PKM) to suppress glucose uptake by stromal cells of the metastatic niche and cells located in distant organs (86-88). Metastatic colonization in brain and lungs was observed after intracardiac injection of MDA-MB-231 cells into mice pretreated with endocytic vesicles containing miR-122, whereas no metastases were detected in controls (85). From a clinical point of view, it has been noted that miR-122 levels in the circulation correlate with metastatic progression in BC patients (89). Figure 3 shows the MOA of exosometransferred BC promoting miRs-19a, -105, -122 and -223.

$m i R-223$ : It has been shown previously that interleukin 4 (IL4) released by CD4+ T-cells can induce tumor-associated macrophages, which can promote BC metastasis $(90,91)$. In order to resolve the MOA underlying these observations, it was shown that co-culture of IL4-activated macrophages and $\mathrm{BC}$ cells is associated with transfer of miR-223 containing exosomes to $\mathrm{BC}$ cells (SKBr and MDA-MB-231) leading to 


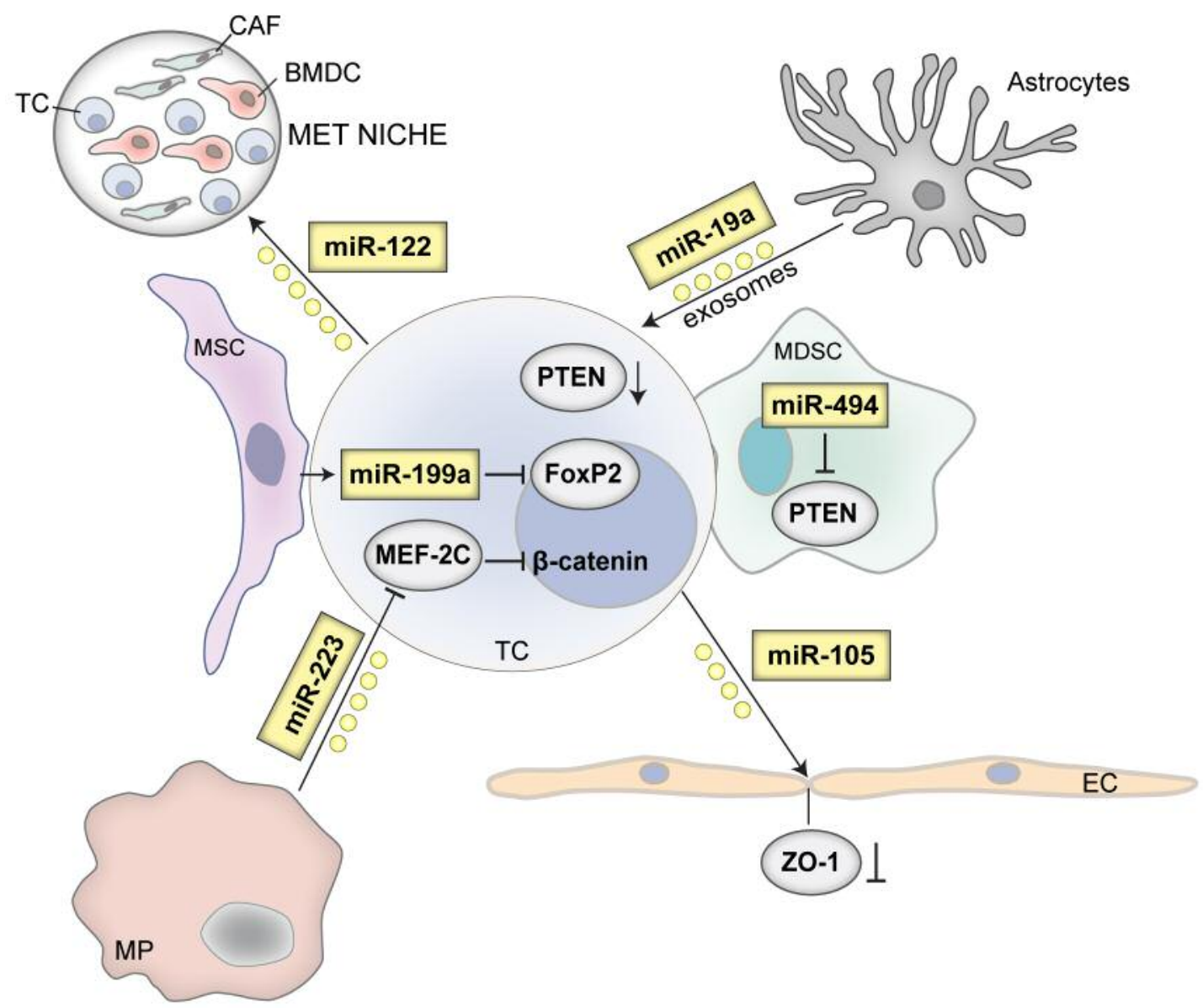

Figure 3. miRs promoting BC-metastasis by interaction of tumor cells with stromal cells or by miR-based exosome transfer between tumor cells and stromal cells or vice versa. Exosomes are displayed as small circles. BMDC: Bone marrow-derived cell; CAF: cancer-associated fibroblast; EC: endothelial cell; FoxP2: forkhead box P2; MDSC: myeloid-derived suppressor cell; MEF-2C: monocyte enhancer factor 2C; MET NICHE: metastatic niche; MP: macrophage; MSC: mesenchymal/stromal stem cell; PTEN: phosphatase and tensin homolog; TC: tumor cell; ZO-1: zonula occludens-1.

their increased invasiveness (92). Treatment of macrophages with ASO directed against IL4 decreased invasiveness of SKBr and MDA-MB-231 cells (92). miR-223 promotes invasiveness by targeting monocyte enhancer factor $2 \mathrm{C}$ (MEF-2C) (92). Reduction of MEF-2C has been linked to nuclear accumulation of $\beta$-catenin, which promotes cell migration (93). In vivo POC metastasis-related data as well as a correlation between the expression status of miR-223 and $\mathrm{BC}$ metastasis are not yet available.

\section{Breast Cancer Metastasis Suppressing miRs}

In this chapter we discuss different classes of miRs. According to the selected categories they interfere with diverse signaling pathways, the cytoskeleton and its modulators, with a network of metastatic regulators in BC cells, or are involved in tumor cell/stromal interactions.
Finally, we discuss additional promising miRs which warrant further validation regarding their anti-metastatic role in $\mathrm{BC}$.

miRs which target diverse signaling pathways. miR-148a was identified by bioinformatic analysis of BC patient databases. There is a correlation between the low expression of miR-148a in higher grade tumors and a higher likelihood to develop metastases and poor prognosis especially in $\mathrm{BC}$ patients with basal and luminal B subtypes (94). In 4T1 and MDA-MB-231 BC cells, ectopic expression of miR-148a did not affect cell growth, viability in culture or in vitro migration (94). However, for both cell lines there was a reduction of lung metastases $(\geq 50 \%)$ observed after fat pad implantation of cells ectopically expressing miR-148a. It was shown that the extravasation process of circulating tumor cells (CTC) and therefore the access to lung parenchyma was suppressed by miR-148a (94). Wingless/integrated1 (Wnt1) 


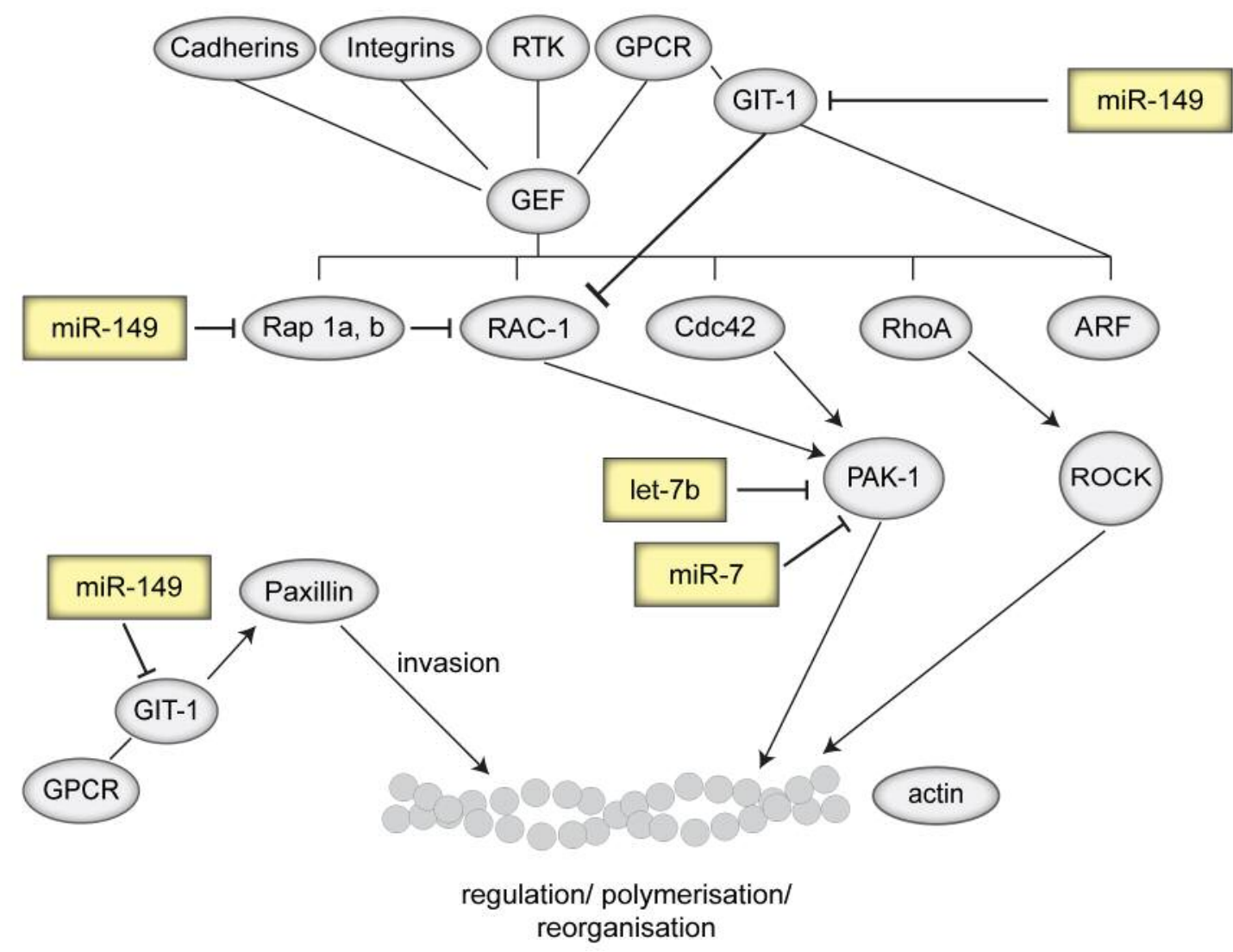

Figure 4. miRs suppressing breast cancer metastasis by modulation of cytoskeletal components. Arrows indicate activation. Actin is displayed as the major downstream effector of miRs let-7b, miR-7 and miR-149. ARF: ADP-ribosylation factor GTPase activating factor; cdc 42: cell division cycle 42 homolog; GEF: guanine nucleotide exchange factor; GIT-1: G-protein coupled receptor interacting protein-1; GPCR: G-protein coupled receptor; PAK-1: p21-activated protein kinase; RAC-1: Rac-related C3 botulinum toxin substrate 1; Rap 1a, b: ras related protein 1a, b; RhoA: ras homologue A; ROCK: Rho-associated kinase; RTK: receptor tyrosine kinase.

and neuropilin-1 (NRP1) were identified as direct targets for miR-148a (94). Wnt-1 induced Wnt signaling can promote EMT and metastasis $(95,96)$ and NRP1 functions as mediator of cell growth, survival and metastasis $(97,98)$.

miR-148b: In a retrospective study, miR-148b and additional $15 \mathrm{miRs}$ were found to be associated with relapse in BC patients (99). Increased miR-148b levels mediate stronger adhesion, anoikis and reduce invasion of BC cells in vitro (99). miR-148 does not affect tumor cell growth in vitro, however in vivo tumor growth and lung metastasis are suppressed due to alteration of survival and extravasation (99). Direct targets affected by miR-148b include metastasis-related mRNAs encoding integrin subunit $\alpha 5(100,101)$, ROCK1, PIK3CA, NRAS and colony-stimulating factor-1 (CSF-1).

$m i R-335:$ miR-335 was identified by screening MDA-MB231 cells (BC subtype Her2 ${ }^{+}$) and subclones that are highly metastatic to the bones or lungs for decreased expression of miRs in all metastatic sublines (102). miR-335 reduces invasion, but does not affect proliferation of BC cell lines (102). Restoring miR-335 expression in LM2 cells (subline of MDAMB-231 highly metastatic to the lungs) through retroviral transduction reduced lung colonizing activity of these cells by more than fivefold (102). Tenascin C and SRY-box containing transcription factor 4 (SOX4) have been identified as invasionrelated direct targets of miR-335 (102). Tenascin C is a glycoprotein of the extracellular matrix (ECM) highly expressed during development, tissue repair and in the stroma of some tumors (103). SOX4 is a transcription factor which regulates progenitor cell development and migration (104) and functions as a master regulator of EMT by controling expression of histone-lysine-N-methyltransferase enhancer of zeste homolog 2 (EZH2) and epigenetic reprogramming (105). miR-335 can also inhibit migration of $\mathrm{BC}$ cells through targeting the oncoprotein c-MET (106). In human BC, miR-335 is silenced through genetic and epigenetic mechanisms (107) and is inversely correlated with relapse in distant organs (102). 
miRs interfering with cytoskeletal targets and their modulators. Let-7: In humans, the lethal 7 (let-7) family of miRs consists of 13 members with both overlapping and distinct functions (108). In BC, let-7 functions as a regulator of self-renewal and tumorigenicity (109). Let-7 inhibits BC cell migration and invasion as well as lung metastasis of tail vein injected MDA-MB-231 cells expressing transfected let7 in comparison to controls (110). Genes involved in the actin cytoskeletal pathway and disassembly of focal adhesions such as p21-activated protein kinase-1 (PAK1) (Figure 4), diaphanous homolog 2 (DIAPH2), radixin (RDX) and integrin subunit $\beta 8$ have been identifed as direct targets of let-7 (110). Further studies have revealed a raf kinase inhibitory related protein (RKIP) based pathway for induction of let-7 with subsequent induction of invasion and metastasis promoting genes $(111,112)$. RKIP has been identified as an inducer of let-7 which inhibits the leucine zipper family transcription factor BTB domain and CNC homolog 1 (BACH1) (113) and the DNA-binding protein high-mobility group A2 (HMGA2) (114). Down-regulation of let-7b results in expression of BACH1- and HMGA2-suppressed metastasis-promoting genes such as the zinc-finger transcription factor SNAIL homolog 1 (SNAI1), MMP-1, CXCR4 and osteopontin (OPN) $(111,112)$. Depletion of BACH1, HMGA2 or both decreased the metastasis of 1833 cells, a subline of MDA-MB-231 cells specifically metastatic to the bones (112). Patients with high activity of the pathway outlined above have a markedly greater risk of metastases compared to those with less active pathway $(111,112)$.

In addition, a role for let-7a related to $\mathrm{BC}$ metastasis has been defined (115). Let-7a suppresses $\mathrm{BC}$ migration and invasion through down-regulation of $\mathrm{C}$-C chemokine receptor 7 (CCR7) (115) and transfection of synthetic let-7a decreases BC cell invasion in zebrafish embryo animal models (115). An inverse correlation between expression of CCR7 and let-7a has been noted in BC patients (115).

miR-149: Two groups have identified miR-149 as a miR, which inhibits BC metastasis by modulating downstream targets of integrin signaling $(116,117)$ (Figure 4). MDA-MB231 cells transfected with miR-149 exhibited severely impaired spreading on collagen gels and haptotactic cell migration (116). The small GTPases Rap1a and Rap1b (118, $119)$ as well as the G-protein coupled receptor interacting protein-1 (GIT-1) (120), an ADP-ribosylation factor GTPase activating protein (ArfGAP), were identified as direct targets of miR-149 $(116,117)$. Inhibition of Rap1a and Rap1b by miR-149 results in aberrant src and RAC- 1 activation, thereby promoting invasion (116). Low levels of miR-149 leads to high levels of GIT-1 expression, which stabilizes integrin $\alpha 5 \beta 1$ and paxillin proteins, thus inhibiting adhesion, migration and metastasis (117). MDA-MB-231 cells transfected with miR-149 exhibited decreased lung colonization after tail vein injection $(116,117)$. From a clinical perspective, low levels of
miR-149 are associated with advanced stages of BC and lymph node metastasis $(116,117)$.

miRs that target networks of pro-metastatic regulators. miR7: miR-7 has been identified as a BC invasion and metastasis inhibitory miR, which regulates multiple targets and pathways (121). The following have been shown to be negatively regulated by miR-7: transcription factor homeobox protein $\mathrm{B} 3$ (HoxB3) (122), PAK-1 (Figure 4) (123), focal adhesion kinase (FAK) (124), krüppel-like factor 4 (KLF4) (125), histone methyltransferase SET domain containing 8 (SET8) (126) and EGFR (127), which function as promoters of tumor growth, migration, invasion and metastasis and are highly interconnected. Inhibition of HoxB3 by miR-7, by targeting the 3'-UTR of its mRNA, leads to the expression of tumor suppressors Ras associated domain family 1A (RASSF1A) and claudin 6, due to decreased promoter methylation (122). Down-regulation of SET8, a histone H4lysine 20 (H4K20) specific monomethyltransferase (126) by miR-7 is an important aspect of the epigenetic function of miR-7. Downregulation of the well- documented promoters of motility PAK1, FAK and EGFR enables miR-7 to decrease metastasis $(128,129)$. Ectopic expression of miR-7 in BC cell lines such as MDA-MB-435 and MBA-MB-231 inhibits growth, migration and invasion in vitro $(121,123)$. Forced expression of miR-7 in MDA-MB-435 cells decreased primary tumor growth 1.5 fold after fat pad implantation and no invasive lesions were observed, due to encapsulation (124). In addition, miR-7 functions as a suppressor of metastasis of BC-derived CSC to the brain, but not to the bones, through down-regulation of KLF4 (125), an essential gene product for pluripotent stem cells promoting their self-renewal (130). KLF4 also correlates with an aggressive phenotype in early $\mathrm{BC}$ (131). The prognostic relevance of miR-7 in BC patients remains to be investigated.

$m i R-29 b$ : miR-29b is induced by GATA-family of transcription factors 3 (GATA3) (132), which is involved in mammary gland morphogenesis and luminal cell differentiation $(133,134)$. GATA3 is expressed at higher levels in luminal versus basal $\mathrm{A}$ and $\mathrm{B}$ subtypes of $\mathrm{BC}$ consistent with its luminal localization. A correlation was found between higher levels of GATA3 and better survival in BC patients $(135,136)$. miR-29b promotes luminal differentiation and targets a network of angiogenic and prometastatic regulators such as vascular endothelial growth factor isoform A (VEGFA), angiopoietin-like 4 (ANGPTL4), platelet-derived growth factor (PDGF), lysyl-oxidase (LOX), MMP-9, TGF $\beta$ and integrin subunits $\alpha 6$ and $\beta 1$ (132), which modify the tumor microenvironment. After orthotopic implantation of 4T1 cells ectopically expressing miR-29b, fewer and smaller lung metastasis were noted (132). miR$29 \mathrm{~b}$ is enriched in more differentiated BC and normal mammary epithelial cells (132). 


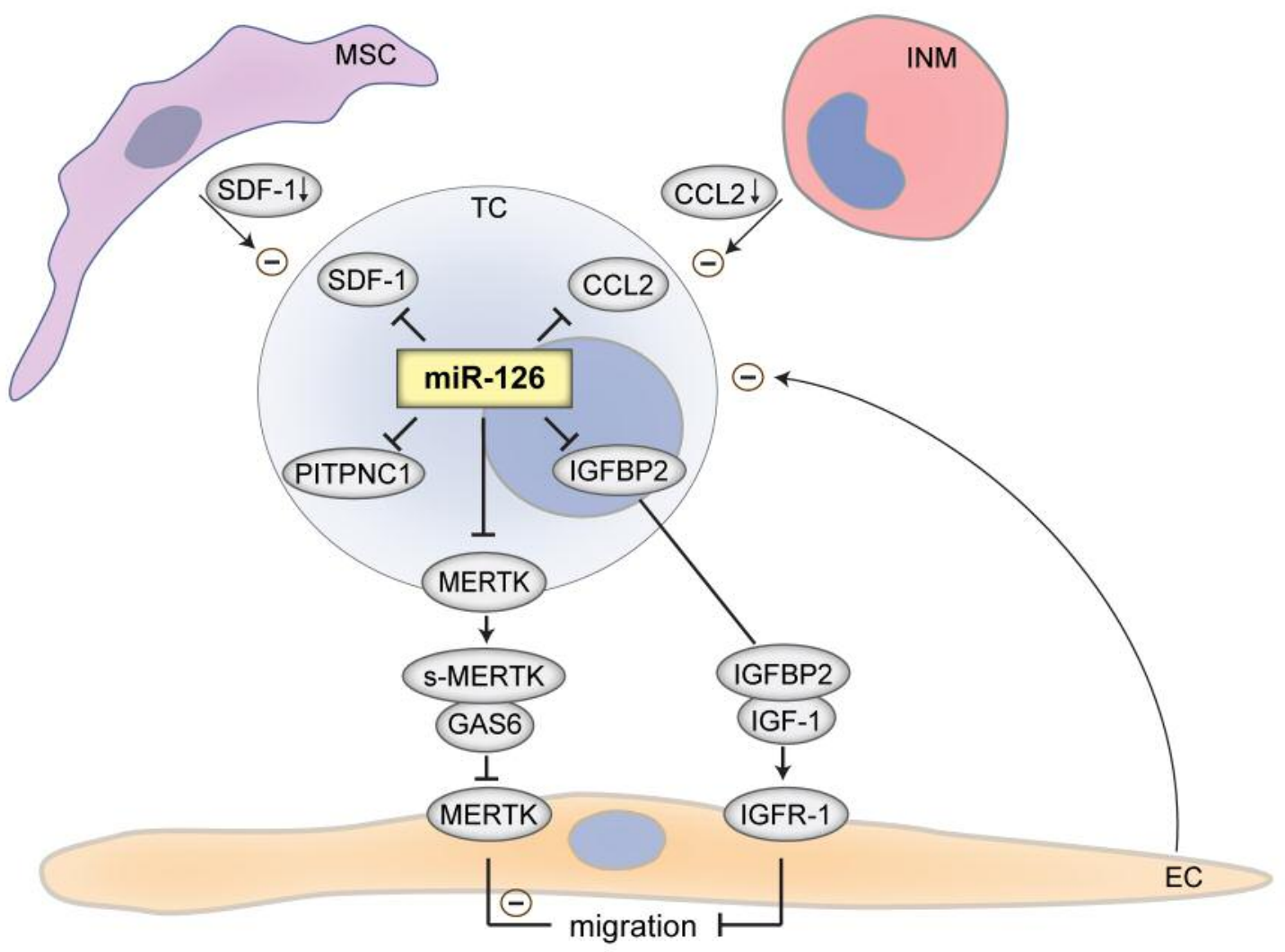

Figure 5. Anti-metastatic function of miR-126 is mediated by inhibition of recruitment of stromal cells by breast cancer cells. miR-126 inhibits recruitment of MSC, INM and EC cells by tumor cells through inhibition of SDF-1 and CCL2 as well as inhibition of IGF-1/IGF-1R and MERTK signaling. CCL2: CC chemokine ligand 2; EC: endothelial cell; IGFBP2: insulin-like growth factor binding protein 2; IGF-1: insulin-like growth factor-1; IGFR-1: insulin-like growth factor receptor-1; INM: inflammatory monocyte; MERTK: c-MER tyrosine kinase; s-MERTK: soluble-MERTK; MSC: mesenchymal stem cell; PITPNC1: phosphoinositol transfer protein, cytoplasmic 1; SDF-1: stromal-derived factor-1; TC: tumor cell.

\section{miRs Involved in Tumor Cell/Stromal Cell Interaction}

miR-126: miR-126 was identified as a miR down-regulated in $\mathrm{BC}$ cells according to their metastatic potential (137). miR-126 exerts its anti-metastatic function by suppressing the recruitment of endothelial cells (ECs) (137), MSCs and inflammatory monocytes (138) (Figure 5).

In the Boyden chamber system, miR-126 overexpressing BC cells inhibit recruitment of human umbilical vein endothelial cells (HUVECs) (137). miR-126 silencing in MDA-MB-231 cells increased lung metastatic colonization and systemic colonization of multiple organs such as liver, bone and brain (137). Direct targets of miR-126 include insulin-like growth factor binding protein 2 (IGFBP2), cMER tyrosine kinase (MERTK) and phosphoinositol transfer protein, cytosplasmic 1 (PITNC1) (137). Individually and in combination they were shown to suppress the ability of LM2 and CN34-LM1A BC cells (a highly metastatic subline derived from ER- CN34 cells, which originate from pleural $\mathrm{BC}$ cells) to recruit ECs (137). In the extracellular space IGFBP2 forms a complex with insulin-like growth factors 1 and 2 (IGF1 and 2) and enhances IGF-type 1 receptor activation on ECs promoting chemotaxis by increasing extracellular levels of IGF-1 (139). MERTK cleaved from metastatic BC cells promotes EC recruitment by competitively antagonizing its ligand growth-arrest specific 6 (GAS6) as a decoy receptor to endothelial MERTK receptors preventing GAS6 from inhibiting EC migration mediated by binding to the MERTK receptor (140). Neutralization of negative chemotactic factor GAS6 leads to enhanced endothelial cell chemotaxis. PITPNC1 is a promoter of EC migration by enhancing IGFBP2 levels (141). Patients whose primary BC displayed overexpression of these genes were significantly more likely to develop distal metastases and displayed shorter metastases-free 
survival (137) and reduced expression of miR-126 correlates with poor metastasis-free survival of BC cells .

Another property of miR-126 expressed in BC cells is the recruitment of MSCs and inflammatory monocytes, both promoting BC metastasis (138). 4T1 cells transduced with miR-126 did not exhibit a difference in proliferation and migration in comparison to non-transfected 4T1 cells, but rather showed suppressed formation of lung metastases after surgical removal of the primary tumor from fat pads (138). Stromal-derived factor 1 (SDF-1), the ligand of CXCR4, was identifed as a direct target of miR-126. Down-regulation of SDF-1 results in suppression of MSC recruitment (142). Recruitment of inflammatory monocytes is inhibited by miR126 indirectly by down-regulation of CCL2 (138). Recruitment of MSC and formation of a paracrine loop with tumor cells enhances tumor cell invasion and metastasis (72), additionally inflammatory monocytes might promote intravasation later in tumor progression (81). miR-126 is located in an intron of host gene Egfl7 and is down-regulated in cancer cells by methylation (138).

\section{Further Breast Cancer Metastasis-suppressive miRs}

In the following we summarize briefly BC metastasissuppressing miRs which inhibit migration, invasion and metastasis of BC cells with pending or early clinical validation with respect to prognosis of $\mathrm{BC}$ patients and are awaiting broader confirmation of their relevance in this context as well as extension of MOA studies.

miR-22 induces cellular senescence in BC cells. It is down-regulated in $\mathrm{BC}$ specimens and mediates translational inhibition of genes counteracting senescence such as CDK6, sirtuin 1 (SIRT1) and transcription factor specificity protein 1 (Spl) (143). In a fat-pad injection based MDA-MB-231 tumor model, lung metastases are inhibited by ectopical expression of miR-22 (143).

miR-30 is reduced in BC-tumor-initiating cells allowing them to maintain their self-renewal and inhibiting their apoptosis (144). miR-30 inhibition leads to up-regulation of its targets integrin subunit $\beta 3$ and ubiquitin-conjugating enzyme 9 (ubc9) (144). Ectopic expression of miR-30 in SKBR derived mammospheres (subtype HER2+) inhibits lung metastases (144)

miR-34a blocks osteoporosis and bone metastasis by inhibition of osteoclastogenesis and TGF $\beta 2$ as shown in a miR-34 knock-out transgenic mouse model (145). It also represses EMT by targeting tumor protein D52 (TPD52), an oncogene expressed in BC (146).

miR-124 targets transcription factor SNAIL homolog 2 (SNAI-2) (147) leading to up-regulation of E-cadherin (148). Lentivirus-based delivery of miR-124 into MDA-MB-231 cells suppresses colony formation in vitro and metastases in vivo.
miR-145 targets cell surface glycoprotein mucin-1 (MUC1) (149) and has no impact on the growth of BC cells. miR145 silencing of MUC-1 suppresses lung metastases in an experimental metastases model (150).

miR-193 targets urokinase plasminogen activator (uPA) (151), a component of the plasminogenolytic system with a well documented role in BC metastasis (152). Ectopic expression of miR-193b in MDA-MB-231 cells inhibits orthotopic tumor growth and formation of spontaneous pulmonary metastases (152). miR-193 is associated with clinical BC metastases (152).

miR-205 targets VEGF and human epidermal growth factor receptor 3 (HER3). Ectopic expression of miR-205 in MDA-MB-231 cells inhibits cell proliferation, invasion, anchorage independent growth and experimental metastases to the lungs (153).

miR-320a acts by suppressing metadherin (MTDH) expression and is down-regulated in $\mathrm{BC}$ tissues and cell lines (154). MTDH expression is related to breast cancer progression (155). miR-320a suppresses lung metastases of MDA-MB-231 cells (154).

miR-421 is down-regulated in BC and down-regulation correlates with lymph node metastasis, recurrence and metastasis (156). miR-421 targets metastasis-associated protein-1 (MTA-1), which is involved in chromatin remodeling (157). miR-421 knock-down leads to invasion and metastasis of MCF-7 cells and overexpression in MDA-MB-231 cells suppresses invasion and metastasis (156).

\section{miRs with Context-dependent Breast Cancer Metastasis-promoting or -suppressive Properties}

miR-200: The miR-200 family consists of miRs-200 a,b,c, miR-429 and miR-141 which share the same seed sequence (158). miR-200 can inhibit EMT by targeting the E-cadherin repressors zinc finger E-box binding homeobox 1 and 2 (ZEB1 and ZEB2) (159), but can also promote EMT via exosomes by mechanisms yet to be resolved (160). It is able to enhance mesenchymal epithelial transition (MET) (160). In the following we comment on the context-dependent proand anti-metastatic function of miR-200 in BC (Figure 6).

Pro-metastatic function of miR-200: It has been observed that endocytic vesicles containing miR-200 are secreted from metastatic murine and human $\mathrm{BC}$ cell lines and their transfer to non-metastatic BC cells alters gene expression and promotes EMT. In vivo experiments were performed with syngeneic mammary tumor cell lines derived from a single spontaneous mammary tumor with different metastatic performance (160). Incubation of 4T1-derived exosomes enhances lung colonization of 4T07 cells, which are unable to colonize distant organs after tail vein injection (160). miR200 secreted from CA1a (Her2+ subtype, highly metastatic) primary mammary tumors promote lung colonization of tail- 


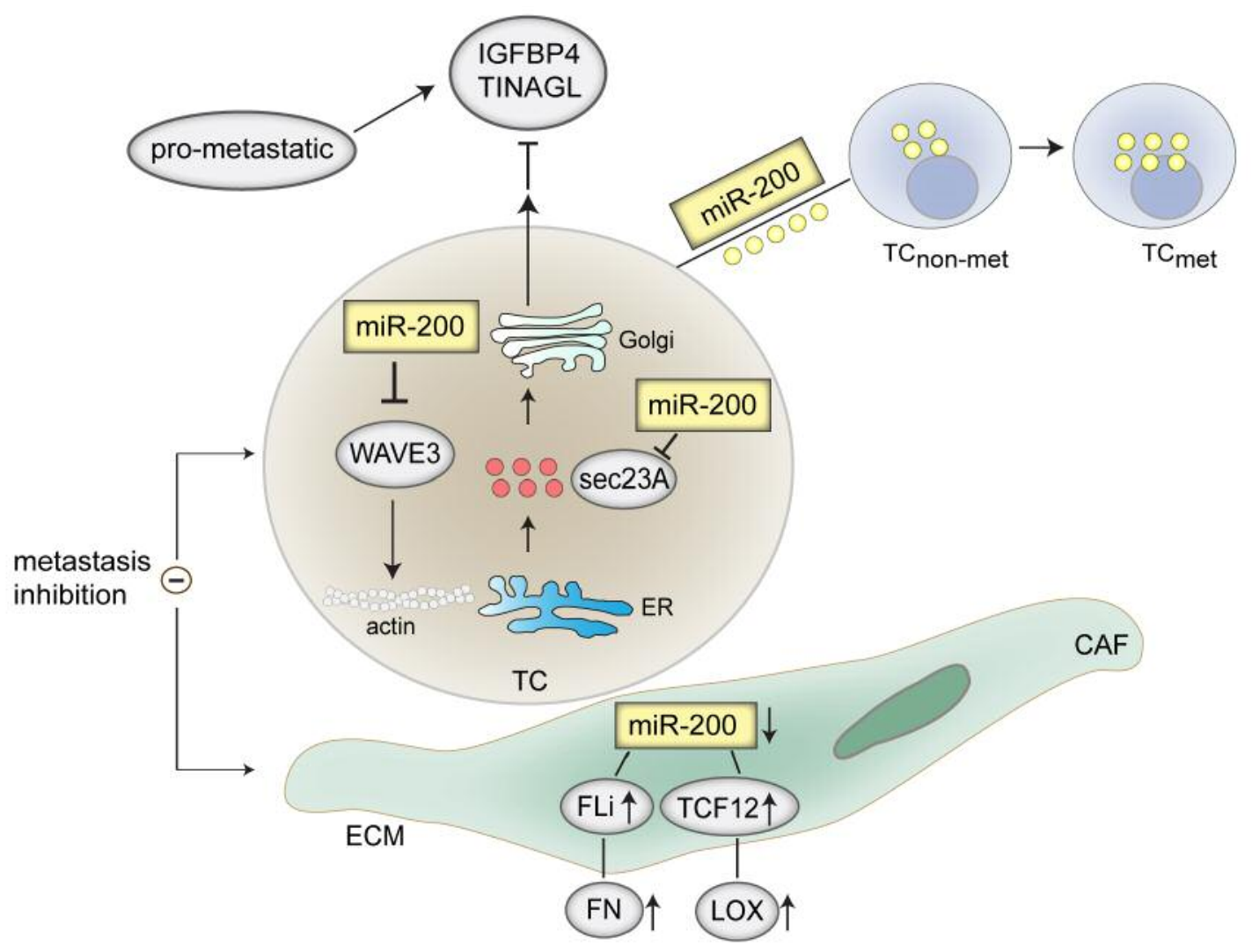

Figure 6. miR-200 promotes or inhibits metastasis of breast cancer cells in a context-dependent manner. Pro-metastatic actions of miR-200 can be mediated by exosomes or through inhibition of secretion of anti-metastatic proteins and inhibition of metastasis is based on modulation of actin interaction with WAVE3 and re-organisation of the ECM in CAFs. Exosomes and secretory vesicles are displayed as green or red small circles. CAF: Cancer-associated fibroblast; ECM: extracellular matrix; ER: endoplasmic reticulum; Fli-1: Friend leukemia integration-1; FN: fibronectin; IGFBP4: insulin-like growth factor binding protein 4; LOX: lysyl oxidase; sec 23A: sec 23 homolog A (S. cerevisiae); TC: tumor cell; TCF12: transcription factor 12; TINAGL: tubuli interstitial nephritis antigen-like 1; WASP: Wiskott Aldrich Protein; WAVE3: WASP verprolin homologue 3.

vein injected MDA-MB-231 cells (160). miR-200 was shown to target sec 23 homolog a (sec 23a), an essential component of vesicles transporting proteins from the endoplasmic reticulum (ER) to the Golgi apparatus and thus influencing the BC secretome $(161,162)$. Sec 23 a mediates secretion of metastasis-suppressive proteins including insulin-like growth factor binding protein 4 (IGFBP4) and tubulo interstitial nephritis antigen-like 1 (TINAGL1) $(163,164)$. IGFBP4 and TINAGL1 are asscociated with metastasis-free survival in a BC-related clinical data set (165).

Metastasis-inhibiting function of miR-200: It has been reported that down-regulation of WASP verprolin homologous 3 (WAVE3), a member of Wiskott-Aldrich syndrome protein (WASP) actin cytoskeleton remodeling family of proteins by miR-200 inhibits the invasive phenotype of MDA-MB-231 cells (166). WAVE mediates remodeling of actin-cytoskeleton interactions critical for motility, migration and invasion of transformed cells (167). Another role of miR-200 in modulation of $\mathrm{BC}$ metastasis was found in the context of cancer-associated fibroblasts (CAF)-BC cell interactions (168). Down-regulation of miR-200 was shown to activate normal fibroblasts to CAFs (168), resulting in up-regulation of transcription factors Friend leukemia integration (Fli-1) (169) and transcription factor 12 (TCF12) (13). These factors induce remodeling of the ECM by up-regulating fibronectin and LOX (170) thus promoting metastasis. Ectopic expression of miR-200 in CAFs significantly decreased lung metastatic burden after co-injection with MDA-MB-231 BC cells in orthotopic models (168).

Overexpression of miR-200 has been shown to be asociated with increased risk of metastasis in BC $(161,171)$. For the opposite correlation, no clinical data are available. These seemingly counterintuitive results, as outlined above might be due to cell-type (context)-dependent functions of miR-200 and/or due to its dichotonomous role in metastasis. miR-200 might counteract early steps of invasion and 


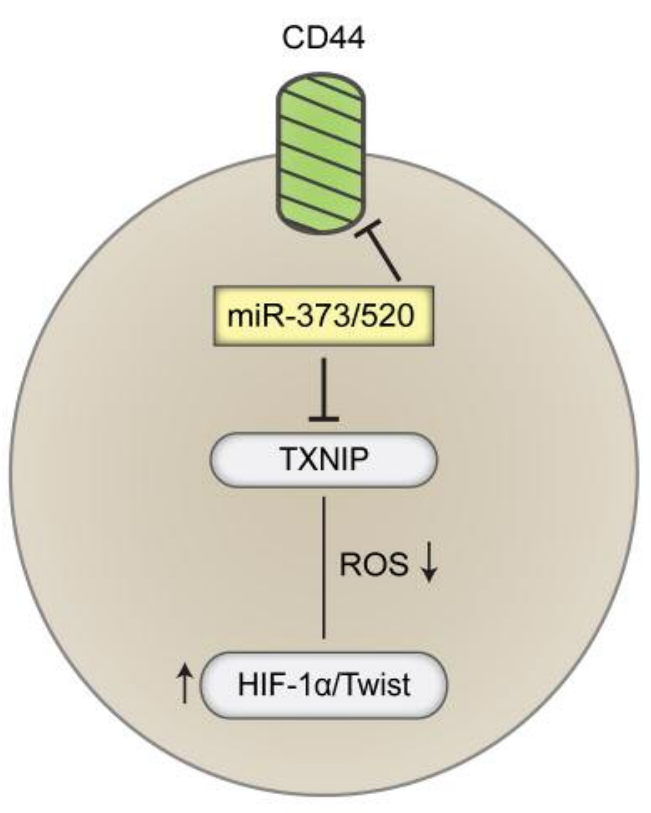

Pro-metastatic

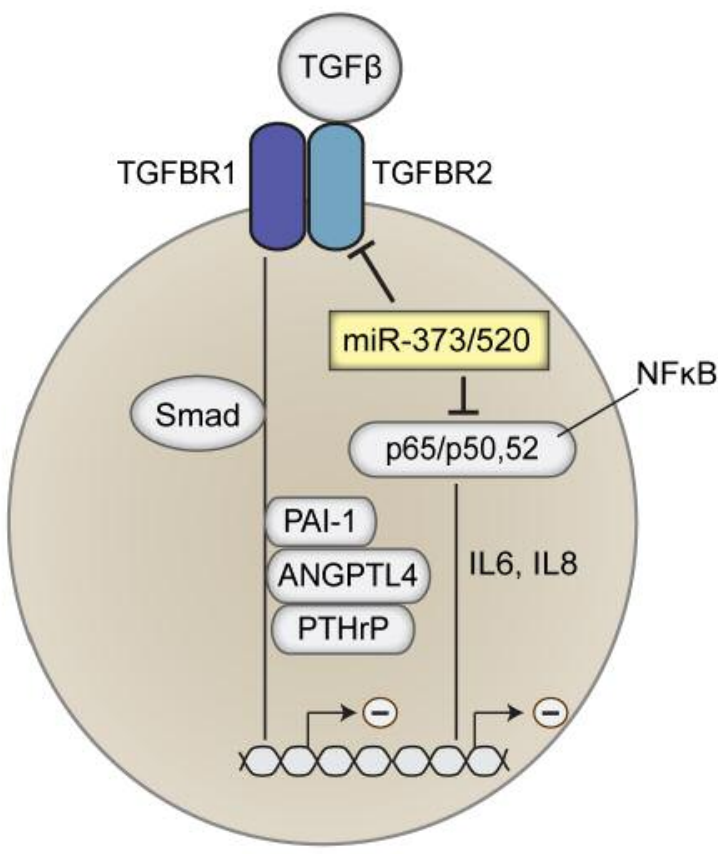

Anti-metastatic

Figure 7. Pro- and anti-metastatic functions of miR-373/520. Pro-metastatic function of miR-373/520 in breast cancer cells is mediated by degradation of CD44 and activation of HIF-1 $\alpha /$ Twist signaling. Anti-metastatic function of miR-373/520 is based on inhibition of TGF $\beta$ - and NFKB signaling. ANGPTL4: Angiopoietin-like 4; CD44: cluster of differentiation 44; HIF-1 $\alpha$ : hypoxia-inducible factor 1 $\alpha$; interleukin 6,8: interleukin 6 or 8; PAI-1: plasminogen activator inhibitor-1; PTHrP: parathyoid hormone-related protein; ROS: reactive oxygen species; Smad: contraction of Sma and Mad (mothers of decapentaplegic); TGF $\beta$ : transforming growth factor $\beta$; TGFBR1,2: transforming growth factor $\beta$ receptor 1,2; TXNIP: thioredoxin-interacting protein.

migration and promote colonization of the parenchyma of distinct organs by enhancing MET $(160,161)$. On the other hand miR-200 might be down-regulated at the invasive front of breast tumors and up-regulated in the resulting metastases (172). More work addressing the MOA of miR-200 in BC meastasis is needed to resolve these issues.

miR-373/520c: The miR-373/520 family consists of three different clusters possessing an identical seed region (173). In BC-related experimental systems miR-373/520c can act as an oncogene or as a tumor suppressor in a contextdependent manner (174-176) (Figure 7). Ectopic expression of miR-373/520 confers migratory properties to nonmigratory MCF-7 cells $(174,175)$. In MDA-MB-231 cells (ER-, aggressively invasive) overexpression of miR-373 blunts invasive capacity (174) and on the other hand in MDA-MB-435 cells, which express endogeneous miR373/520, down-regulation of miR-373/520 inhibits migration and invasion (176). MCF-7 cells ectopically expressing miR$373 / 520$ give rise to metastatic nodules in the lungs and bone metastasis in the skull after tail vein injection $(174,176)$. There are no in vivo metastasis-related data available for the metastasis suppressive function of miR-373/520. Two basic mechanisms have been shown to be connected to the metastasis-promoting function of miR-373/520. One is based on down-regulation of cell surface receptor cluster of differentiation 44 (CD44), a direct target of miR-373/520 (174). The other one is based on down-regulation of thioredoxin-interacting protein (TXNIP) and subsequent activation of the hypoxia-inducible factor $1 \alpha(\mathrm{HIF}-1 \alpha) /$ Twist signaling pathway (175). The tumor-suppressive function of miR-373/520 is mediated by inhibition of NFKB signaling through direct targeting of NFKB subunit p65 (176) and down-regulation of TGF $\beta$ signaling due to direct suppression of transforming growth factor $\beta$ receptor 2 (TGFBR2) (176). The modulation of these pathways leads to decreased secretion of pro-inflammatory molecules such as interleukin 6 and 8 (IL6 and IL8) and TGF $\beta$-dependent molecules such as angiopoietin-like 4 (ANGPTL4), parathyroid hormonerelated protein (PTHrP) and plasminogen activator inhibitor1 (PAI-1) (176). In line with the preclinical data, controversial clinical correlations have been reported. Expression of miR-373/520 in BC specimens correlated with a higher probability of metastasis in one study (174), in another study an inverse correlation between miR-373/520 
levels and lymph node metastases has been noted, especially in ER-patients (4). However, due to the heterogeneity of BC with respect to subtypes as outlined previously, the small sample size in both studies might not be sufficient for correlation analysis.

\section{Steady-state RNA Levels of Selected miR in Breast Cancer and Corresponding Normal Tissues}

The data were derived from The Cancer Genome Atlas (TGCA) and are shown in Figure 8. Prometastatic miRs -105, $-182,-21$ and -9 are up-regulated in breast cancer tissues in comparison to matching normal tissues (Figure 8A), whereas anti-metastatic miRs $-126,-145,-205$ and -335 are downregulated (Figure $8 \mathrm{~B}$ ).

\section{Potential Relevance and Current Bottlenecks of miR-directed and/or -based Therapies}

For the treatment of $\mathrm{BC}$ metastasis several scenarios can be envisaged: (i) therapy initiation prior to dissemination (clinically uncommon), (ii) therapy initiation after dissemination prior to formation of overt metastases, or (iii) initiation of therapy after formation of overt metastases. Significant numbers of disseminated tumor cells are present in blood, bone marrow and distant organs of BC patients upon initial presentation in the clinic $(177,178)$. Therefore, effective anti-metastatic therapy should, in addition to interference with migration and invasion, also affect proliferation and survival of disseminated tumor cells. Anti-metastatic therapy also needs to target established metastases otherwise its utility would be restricted to (rather unlikely) long-term prophylactic settings.

In contrast to therapies focusing on one defined target, miR-directed therapies are able to concurrently target multiple pathways involved in dissemination, proliferation and survival. In addition, modulation of miRs also can affect epigenomic modifications, which modulate a variety of different cancer-related processes.

The potential of miR-related agents to be efficacious against metastatic disease has been described in the preceding chapters of this review. These include on one side application of agents that interfere with tumor/metastasis promoting miRs. Furthermore, miRs or nucleic acid derivatives with miR functionality may be applied on the other side to elicit functionalities of tumor/metastasis suppressing or preventing functionalities. Experimental data targeting established metastases in preclinical in vivo models by modulation of miRs are not yet available. Possible modes of intervention, dependent on the function of the specific miR under consideration are inhibition, degradation or reconstitution of its function by replacement therapy.

Inhibition of miR functionalities can be achieved by nucleic acid -derived therapeutics. Examples for such entities include antisense oligonucleotides (ASOs), siRNAs, gapmers, locked nucleic acids (LNA) and antagomirs to name a few. Common features of such 'small' nucleic-acid based entities are chemical modifications introduced to enhance biophysical properties, stability and/or nuclease resistance. Further modifications may include 5' o 3' additions of entities to enhance tissue targeting (e.g. cholesterol (179-183). Other miR-inhibitory agents are antimiR-MASK single-strand ASOs which are complementary to the miR-binding nucleotides in the 3'-UTR of the target RNA. Or miR sponges that harbor multiple (4 to 16) seed binding sites as decoys and duplex RNAs which induce degradation due to RNA interference (RNAi) and hairpin RNAs, which mediate miR degradation (179-183). Finally, small molecule inhibitors may be able to prevent binding of miRs to 3'-UTR seed sequences.

Replacement therapy can in vitro be 'mimicked' by transfection or transduction of pri-miRNA, pre-miRNA or mature miRs, e.g. via liposomes, targeted liposomes or viral transduction. Although such approaches are feasible for proof-of-concept experiments in cultured cells, they cannot be applied for therapeutic approaches. This is mainly because of systemic toxicity and major side effects.

The in vivo delivery of nucleic acids is one (still unsolved) major bottleneck that has hampered nucleic acids from being safely applicable as therapeutic compounds. After the administration of RNAs (or RNA-derivatives/conjugates) the molecules face several physiological barriers: i) serum stability, ii) renal excretion, iii) immunogenicity, iv) extravasation, v) entry into the target cell, and vi) endosomal escape.

To avoid a fast renal clearance, RNAs can be conjugated to polyethylene glycol (PEG) to increase the molecular weight. Furthermore, a conjugation to cholesterol or albumin triggers the binding to lipoproteins in the circulation which enhances the serum half-life (184-186). Another possibility is the formulation into large nanoparticle structures. An advantageous effect of these modifications is that they can also protect the RNA from nuclease-mediated degradation in the circulation and prevent immunogenicity and cytokine release syndrome $(187,188)$.

In contrast to small molecules, RNAs cannot passively cross the cell membrane due to their hydrophilic character and size. Thus, conjugate delivery systems were used to shield the charged nucleic acids and allow a fusion with the cell membrane. Lipid Nanoparticles (LNP) are small lipoplexes that are broadly used for cell culture transfections. In the meanwhile, they were also tested for their suitability as in vivo transfectants $(189,190)$. However, those compounds strongly accumulate in the liver and other filtering organs and are rather cell-type unspecific which makes them likely to cause side effects and toxicity issues (191).

Dynamic PolyConjugates (DPC) consist of different components that can change their mode of action upon mileu 

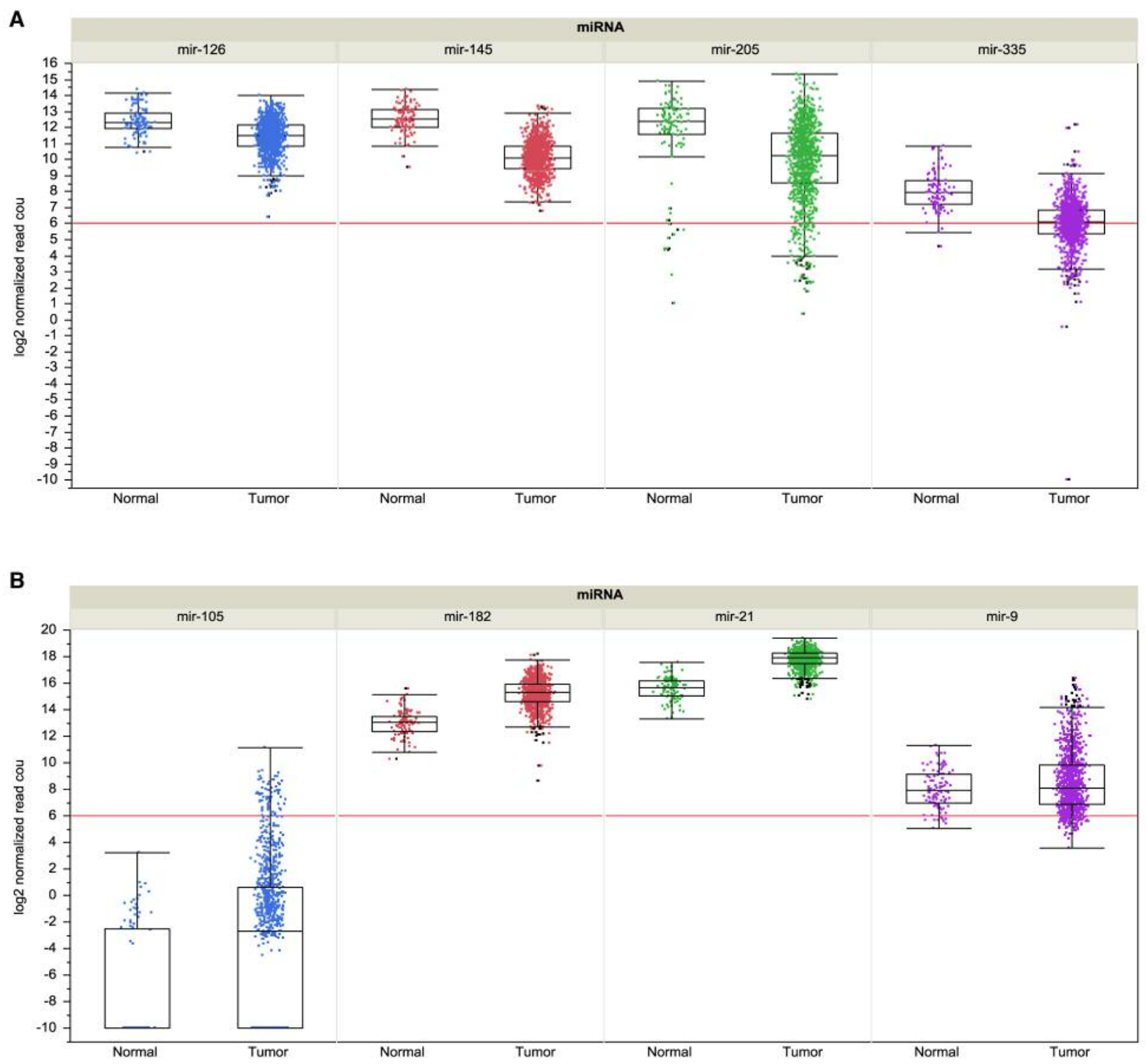

Figure 8. Expression of selected microRNAs in breast cancer in comparison to matched normal tissues. A: Pro-metastatic miRs: miRs -105, -182, -21 and -9; B: Anti-metastatic miRs: miRs -126, -145, - 205 and -335. Steady-state RNA levels corresponding to miR-105, miR-181c and miR-210 based on 1,084 invasive breast cancer samples and 104 matched normal samples derived from cohorts of The Cancer Genome Atlas (TCGA) are shown. Expression was quantified by RNA sequencing and is shown as log2 of normalized read counts. The red lines indicate low versus higher expression. Expression data are shown as box plots. The line in the middle of the box represents the data median, the rectangles show the upper and lower $25 \%$ quartile and $50 \%$ of all data points are included in the rectangle. All other data points, except for outliers are located within the upper and lower whiskers.

changes. The nucleic acid is incorporated into lipohilic polymers which are again shielded by PEG. Thus, the membrane-disrupting agents are covered within the circulation. Upon entry into the endosome, the acidic conditions make the PEG molecules dissociate and unleash the endosomal escape capacity of the lipid polymers. Thereby, the nucleic acid payload is released into the cytosol in a prodrug-like manner $(192,193)$.
The problem that goes along with LNP and DPC synthesis/assembly is, that these structures are often not well defined and rather heterogeneous pools containing molecules of different size and composition. To ensure a population of molecular identical shape, oligonucleotide nanoparticles (ONP) might be a promising solution. RNA molecules are extended at the 3' end with complementary DNA fragments that hybrid into predefined three-dimensional structures (194-196). 
As mentioned earlier the majority of conjugates end up in the liver as the primary filtering organ. To gain a higher degree of tissue specificity, siRNAs were equipped with target cell binding entities. The first major advance and entry into clinical trials was achieved with the addition of $\mathrm{N}$-acetylgalactosamine (GalNAc) that binds with high affinity to the asiologlycoprotein receptor (ASGPR) on hepatocytes. Various chemically stabilized siRNAs that are conjugated on their 3' end with a trivalent GalNAc entity mediate great knockdown efficiencies of respective genes in hepatocytes. Thus, these conjugates are subject to several clinical trials against different indications such as amyloidosis, haemophilia and hypercholesterolemia (197-199).

Although the liver itself provides wide therapeutic possibilities, the targeted delivery of miRNAs to a specific cell type gained more and more interest in the last years. Conjugates of RNAs and cell penetrating entities with targeting ligands, aptamers, or antibodies (-fragments) both avoid a fast excretion and facilitate a specific binding to target cells and receptor-mediated endocytosis (200).

Integrin-binding RGD peptides were successfully used to deliver nanoparticle-packed siRNA to tumor neovasculature (201), and folate-incorporated lipid-based nanoparticles guided nucleic acids to rapid dividing cancer cells that require high amounts of folate (202).

Non-protein-based targeting agents are aptamers, selected nucleic acid binding species. They can be used to bind and deliver siRNA specifically to surface antigens such as the prostate specific membrane antigen (PSMA) (203-205).

Binding entities can be both linked covalently and noncovalently to the RNA-conjugates. One popular covalent approach is to use acid-labile or protease cleavable linkers that are exclusively degraded/cut within the endosome but stable in the circulation (206).

In another concept, haptenylated siRNA is complexed in DPC and delivered with a hapten-binding bispecific antibody to target cells in mice. Thereby, a significant target gene knockdown within tumor cells could be achieved (207).

Song and coworkers used the siRNA complexing agent protamine and fused it to an antibody Fab fragment which was directed against HIV-1 envelope. This complex achieved a specific delivery of siRNA to HIV-infected cells (208).

With respect to the internalization of the bound antibody, suitable receptors were identified in different screens. Especially membrane antigen with high turnover rates and the tendency to trigger receptor-mediated endocytosis lead to a high accumulation of nucleic acid in endosomes. Intracellular routing and recycling pathways of vesicular cargo molecules are also subject to current research $(209,210)$. Nevertheless, the biggest challenge is the entry of the therapeutic nucleic acids to its point of action - the cytoplasm or even the nucleus. The endosomal membrane is an evolutionary conserved barrier to prevent the entry of foreign nucleic acids, e.g. from bacterial or viral origin. Nevertheless, not only viruses evolved mechanisms to overcome this roadblock and accomplish endosomal release. To mimic these mechanisms, various attempts were tried such as the complexation of viral proteins as cell-penetrating entities. The most prominent example is the trans-activating transcriptional activator (TAT)-dervided peptide from human immunodeficiency virus 1 (HIV-1) which was shown to promote delivery of nucleic acids (211). Other examples are penetratin (drosophila), transportan and Pep-1 (HIV) $(212,213)$. However, immune recognition and related toxicity problems limited a significant therapeutic success since many of these compounds are not well tolerated in vivo. Human-derived cell penetrating peptides such as neurturin (NRTN) displayed reduced toxicity but comparable membrane activity (214). Galenics have improved the in vitro transfer of cationic molecules (215). Considering the mode of action of cell penetrating peptides (CPP), many theories were discussed (e.g. proton sponge theory) $(212,216)$. Langel et al. and others put much effort in defining rules and characteristics of CPP and designed artificial hybrids that carry advantageous features for intracellular cargo delivery.

Despite the fact that some clinical trials show promising data, the majority of these (targeted-) approaches must be seen as "early" concepts compared to established therapeutic agents such as small molecules, peptides, proteins or combinations thereof.

Taken together, the delivery bottleneck and other still unresolved issues presently represent serious limitations for clinical applications. Examples are (in addition to delivery) potential issues of removal of complexed DNA by phagocytic immune cells from the bloodstream, off-target effects and resulting toxicity such as cytokine release syndrome and hematological toxicity such as thrombocytopenia and biological stability of these agents in biological fluids and tissues (179183). The detailed discussion of these issues is not in the scope of this review. The responsiveness of $\mathrm{BC}$ cell lines representing different molecular subtypes versus miR antagonists or mimetics with respect to parameters such as migration and invasion, proliferation and survival has to be investigated in more detail. Several in vivo models should be explored to get a more comprehensive picture of the functional consequences of modulation of a specific miR. Regarding clinical evaluation of miR-related agents in cancer patients, Mirna Therapeutics has evaluated an miR-34 mimetic as a replacement therapeutic in patients with hepatocellular carcinoma in a Phase I study. However, due to toxicity issues such as cytokine-release syndrome, the study has been halted (www.mirnarx.com). Other, miR-based cancer-related and metastasis-targeting approaches will be preclinically validated and clinically explored in cancer patients in the up-coming years including their potential as biomarkers for metastatic disease.

\section{Acknowledgements}

$\mathrm{SD}$ is a member of the international doctoral program "i-Target: Immunotargeting of Cancer," funded by the Elite Network of Bavaria. 


\section{References}

1 American Cancer Society: Breast Cancer Facts and Figures 2015-2016. Atlanta: American Cancer Society, Inc 2015.

2 Santa-Maria CA and Gradishar WJ: Changing treatment paradigms in metastatic breast cancer: lessons learned. JAMA Oncol 1: 528-523, 2015.

3 Amedos M, Vicier C, Loi S, Lefebre C, Michels S, Bonnefoi H and Andre F: Precision medicine for metastatic breast cancerlimitations and solutions. Nat Rev Clin Oncol 12: 693-704, 2015.

4 Rivenbark AG, O'Connor SM and Coleman WB: Molecular and cellular heterogeneity in breast cancer: challenges for personalized medicine. Am J Pathol 183: 1113-1124, 2013.

5 Weilbaecher KN, Guise TA and Mac Cauley LK: Cancer to bone: a fatal attraction. Nat Rev Cancer 11: 411-425, 2011.

6 Valastyan S and Weinberg RA: Tumor metastasis: molecular insights and evolving paradigms. Cell 147: 275-292, 2011.

7 Desmedt C, Yates L and Kulka J: Catalog of genetic progression of human cancers: breast cancer. Cancer Metastasis Rev 35: 49-62, 2011.

8 Vanharanta $\mathrm{S}$ and Massague J: Origins of metastatic traits. Cancer Cell 24: 410-421, 2013.

9 Lin S and Gregory RI: MicroRNA biogenesis pathways in cancer. Nat Rev Cancer 15: 321-333, 2015.

10 Bertoli G, Cava C and Castiglioni I: Micro RNAs: New biomarkers for diagnosis, prognosis, therapy prediction and therapeutic tools for breast cancer. Theranostics 5: 1122-1143, 2015.

11 Bartel DP: Micro RNAs. Genomics, biogenesis, mechanism and function. Cell 116: 281-297, 2004.

12 Pillai RS: MicroRNA function: multiple mechanisms for a tiny RNA? RNA 11: 1753-1761, 2005.

13 Bentwich I, Avniel A, Karov Y, Aharonov R, Gilad S, Barad O, Barzilai A, Einat P, Einav U, Meiri E, Sharon E, Spector Y and Bentwich Z: Identification of hundreds of conserved and nonconserved human microRNAs. Nat Genet 37: 766-770, 2005.

14 Denli AM, Tops BB, Plasterk RH, Ketting RF and Hannon GJ: Processing of primary microRNAs by the microprocessor complex. Nature 432: 231-234, 2004.

15 Yi R, Quin Y, Macara IG and Cullen BR: Exportin-5 mediates the nuclear export of pre-microRNAs and short hairpin RNAs. Genes Dev 17: 3011-3016, 2003.

16 Diederichs S and Haber DA: Dual role of argonautes in microRNA processing and posttranscriptional regulation of microRNA expression. Cell 131: 1097-1108, 2007.

17 Czech B and Hannon GJ: Small RNA sorting: matchmaking for argonautes. Nat Rev Genet 12: 19-31, 2011.

18 Peng $\mathrm{Y}$ and Croce CM: The role of microRNAs in human cancer. Signal transduction and targeted therapy 1: 15004, 2016.

19 Reddy KB: MicroRNA (miRNA) in cancer. Cancer Cell Int 15: 38, 2015.

20 Garzon R, Calin GA and Croce CM: MicroRNAs in cancer. Ann Rev Med 60: 167-179, 2009.

21 Svoronos AA, Engelman DM and Slack FJ: OncomiR or tumor suppressor? The duplicity of microRNAs in cancer. Cancer Res 76: 3666-3670, 2016.

22 Schetter AJ, Leung SY, Sohn JJ, Zanetti KA, Bowmann ED, Yanaihara N, Yuen ST, Chan TL, Kwong DL, Au GK, Liu CG, Calin GA, Croce CM and Harris CC: MicroRNA expression profiles associated with prognosis and therapeutic outcome in colon adenocarcinoma. JAMA 299: 425-436, 2008.

23 Cimmino A, Calin GA, Fabbri M, Iorio MV, Ferracin M, Shimizu M, Wojcik SE, Aqeilan RI, Zupo S, Dono M, Rassenti L, Alder H, Volinia S, Liu CG, Kipps TJ, Negrini M and Croce CM: miR-15 and miR-16 induce apoptosis by targeting BCL2. Proc Natl Acad USA 102: 13944-13949, 2008.

24 Calin GA, Cimmino A, Fabbri M, Ferracin M, Wojcik SE, Shimizu M, Taccioli C, Zanesi M, Garzon R, Aqueilan RI, Alder H, Volinia S, Rassenti L, Liu X, Liu CG, Kipps TJ, Negrini $M$ and Croce CM: miR-15a and miR-16-1 cluster functions in human leukemia. Proc Natl Acad Sci USA 105: 5166-5171, 2008

25 Klein U, Lia M, Crespo M, Siegel R, Shen Q, Mo T, AmbesiImpriombato A, Califano A, Migliazza A, Bhagat $G$ and DallaFavera R: The DLEU2/miR-15a/16-1 cluster controls B cell proliferation and its deletion leads to chronic lymphocytic leukemia. Cancer Cell 17: 28-40, 2010.

26 Kitaneh M, Montero AJ and Glück S: Molecular profiling for breast cancer: a comprehensive review. Biomark Cancer 5: 6170,2013

27 Holliday DL and Speirs V: Choosing the right cell for breast cancer research. Breast Cancer Res 13: 215, 2011.

28 O'Donnell KA, Wentzel EA, Zeller KI, Dang CV and Mendell JT: c-Myc-regulated microRNAs modulate E2F1 expression. Nature 435: 839-843, 2005.

29 Si ML, Zhu S, Wu H, Lu Z, Wu F and Mo YY: miR-21mediated tumor growth. Oncogene 26: 2799-2803, 2007.

30 Zhu S, Wu H, Wu F, Nie D, Sheng S and Mo YY: MicroRNA21 targets tumor suppressor genes in invasion and metastasis. Cell Res 18: 350-359, 2008.

31 Asangani IA, Rasheed SA, Nikolova DA, Leupold JH, Colburn $\mathrm{NH}$, Post S and Allgayer H: MicroRNA-21 (miR-21) posttranscriptionally down-regulates tumor suppressor Pdcd4 and stimulates invasion, intravasation and metastasis in colorectal cancer. Oncogene 27: 2128-2136, 2008.

32 Lockett J, Yin S, Li X and Sheng S: Tumor suppressive maspin and epithelial homeostasis. J Cell Biochem 97: 651-660, 2006.

33 Zhu S, Si ML, Wu H and Mo YY: MicroRNA-21 targets the tumor suppressor gene tropomyosin 1 (TPM1). J Biol Chem 282: 14328-14336, 2007.

34 Perry SV: Vertebrate tropomyosin: distribution, properties and function. J Muscle Res Cell Motil 22: 5-49, 2001.

35 Li J, Zhang Y, Zhang W, Jia S, Tian R, Kang Y, Ma Y and Li $\mathrm{D}$ : Genetic heterogeneity of breast cancer metastasis may be related to miR-21 regulation of TIMP-3 in translation. Int J Surg Oncol 2013: 875078, 2013.

36 Huang TH, Wu F, Loeb GB, Hsu R, Heidersbach A, Brincat A, Horiuchi D, Lebbink RJ, Mo YY, Goga A and McManus MT: Up-regulation of miR-21 by Her2/neu signaling promotes cell invasion. J Biol Chem 284: 18515-18524, 2009.

37 Yan LX, Huang XF, Shao Q, Huang MY, Deng 1, Wu QL, Zeng YX and Shao JY: MicroRNA miR-21 overexpression in human breast cancer is associated with advanced clinical stage, lymph node metastasis and patient poor prognosis. RNA 14: 23482360, 2008.

38 Fang L, Du WW, Yang W, Rutnam ZJ, Peng C, Li H, O’Malley YQ, Askeland RW, Sugg S, Lu M, Mehta T, Deng Z and Yang BB: miR-93 enhances angiogenesis and metastasis by targeting LATS2. Cell Cycle 11: 4352-4365, 2012. 
39 Visser S and Yang X: LATS tumor suppressor: a new governor of cellular homeostasis. Cell Cycle 9: 3892-3903, 2010.

40 Li Y, Pei J, Xia H, Ke H, Wang $\mathrm{H}$ and Tao W: LATS2, a putative tumor suppressor, inhibits $\mathrm{G} 1 / \mathrm{S}$ transition. Oncogene 22: 4398-4405, 2003.

41 Paramasivam M, Sarkeshik A, Yates JR 3rd, Fernandez KJ and McCollum D: Angiomotin family proteins are novel activators of the LATS2 kinase tumor suppressor. Mol Biol Cell 22: 37253733, 2011.

42 Hu J, Xu J, Wu Y, Chen Q, Zheng W, Lu X, Zhou C and Jiao D: Identification of microRNA-93 as a functional dysregulated miRNA in triple-negative breast cancer. Tumor Biol 36: 251258, 2015.

43 Lane J, Martin TA, Watkins G, Mansel RE and Jing WG: The expression and prognostic value of ROCK I and ROCK II and their role in human breast cancer. Int J Oncol 33: 585-593, 2008.

44 Bourguignon LY, Zhu H, Shao L, Zhu D and Chen YW: Rhokinase (ROCK) promotes CD44v(3,8-10)-ankyrin interaction and tumor cell migration in metastatic breast cancer cells. Cell Motil Cytoskeleton 43: 269-287, 1999.

45 Ma L, Teruya-Feldstein J and Weinberg RA: Tumor invasion and metastasis initiated by microRNA-10b in breast cancer. Nature 449: 682-688, 2007.

46 Biagioni F, Bossel Ben-Moshe N, Fontemaggi G, Yarden Y, Domany E and Blandino G: The locus microRNA-10b: a critical target for breast cancer insurgence and dissemination. Cell Cycle 12: 2371-2375, 2013.

47 Ibrahim SA, Yip GW, Stock C, Pan JW, Neubauer C, Poeter M, Pupjalis D, Koo CY, Kelsch R, Schüle R, Rescher U, Kiesel L and Götte M: Targeting syndecan-1 by microRNA miR-10b promotes breast cancer cell motility and invasiveness via RhoGTPase- and E-cadherin-dependent mechanism. Int J Cancer 131: E884-896, 2012.

48 Yip GW, Smollich M and Götte M: Therapeutic value of glycosaminoglycans in cancer. Mol Cancer Ther 5: 2139-2148, 2006.

49 Chavez KJ, Garimella SV and Lipkowitz S: Triple negative breast cancer cell lines: one tool in the search for better treatment of triple negative breast cancer. Breast Dis 32: 35-48, 2010.

50 Tao K, Fang M, Alroy J and Sahagian GG: Imagable 4T1 model for the study of late stage breast cancer. BMC Cancer 8 : 228, 2008.

51 Ma L, Reinhardt F, Pan E, Soutschek J, Bhat B, Marcusson EG, Teruya-Feldstein J, Bell GW and Weinberg RA: Therapeutic silencing of miR-10b inhibits metastasis in a mouse mammary tumor model. Nat Biotechnol 28: 341-347, 2010.

52 Zhan Y, Lang X, Li L, Wang B, Ding F, Li Y, Wang X, Zhan Q and Liu Z: MicroRNA-548j functions as a metastasis promoter in human breast cancer by targeting tensin1. Mol Oncol 10: 838-849, 2016.

53 Lo SH: Tensin. Int J Biochem Cell Biol 36: 31-34, 2004.

54 Qadir MI, Parveen A and Ali M: Cdc42: role in cancer management. Chem Biol Drug Res 86: 432-439, 2015.

55 Tang F, Zhang R, He Y, Zou M, Guo L and Xi T: MicroRNA$125 \mathrm{~b}$ induces metastasis by targeting STARD13 in MCF-7 and MDA-MB-231 breast cancer cells. PLoS One 7: e35435, 2012.

56 Leung TH, Ching YP, Yam JW, Wong CM, Yau TO, Jin DY and $\mathrm{Ng}$ IO: Deleted in liver cancer 2 (DLC2) suppresses cell transformation by means of inhibition of RhoA activity. Proc Natl Acad Sci USA 102: 15207-15212, 2005.

57 Nagaraja GM and Kandpal RP: Chromosome 13q12 encoded Rho GTPase activating protein suppresses growth of breast carcinoma cells, and yeast two hybrid screen shows its interaction with several proteins. Biochem Biophys Res Comm 313: 654-665, 2004.

58 Utikal J, Gratchev A, Muller-Molinet I, Oerther S, Kzhyshkowska J, Arens N, Grobholz R, Kannookadan S and Goerdt $S$ : The expression of metastasis suppressor MIM/MTSS1 is regulated by DNA methylation. Int J Cancer 119: 2287-2293, 2006.

59 Saarikangas J, Mattila PK, Varjosolo M, Bovellan M, Harkanen J, Calzada-Wack J, Tost M, Jennen L, Rathkolb B, Hans W, Horsch M, Hyvönen ME, Perälä N, Fuchs H, Gailus-Durner V, Esposito I, Wolf E, de Angelis MH, Frilander MJ, Savilahti H, Sariola H, Sainio K, Lehtonen S, Tapale J, Salminen M and Lappalainen P: Missing-in-metastasis MIM/MTSS1 promotes actin assembly at intercellular junctions and is required for integrity of kidney epithelia. J Cell Sci 124: 1245-1255, 2011.

60 Lei R, Tang J, Zhuang X, Deng R, Li G, Yu J, Liang Y, Xiao J, Wang HY, Yang $\mathrm{Q}$ and $\mathrm{Hu}$ G: Suppression of MIM by microRNA-182 activates RhoA and promotes breast cancer metastasis. Oncogene 33: 1287-1296, 2014.

61 Ma L, Young J, Prabhala H, Pan E, Mestdagh P, Muth D, Teruya-Feldstein, Reinhardt F, Onder TT, Valastyn S, Westerman F, Speleman F, Vandesompele J and Weinberg RA: miR-9, a MYC/MYCN-activated microRNA, regulates Ecadherin and cancer metastasis. Nat Cell Biol 12: 247-256, 2010.

62 Frixen UH, Behrens J, Sachs M, Eberle G, Voss B, Warda A, Löchner D and Birchmeier W: E-cadherin-mediated cell-cell adhesion prevents invasiveness of human carcinoma cells. J Cell Biol 113: 173-185, 1991.

63 Perl AK, Wilgenbus P, Dahl U, Semb H and Christofori G: A causal role for E-cadherin in the transition from adenoma to carcinoma. Nature 392: 190-193, 1998.

64 Nusse R: Wnt signaling in disease and in development. Cell Res 15: 28-32, 2005.

65 Iorio MV, Ferracin M, Liu CG, Veronese A, Spizzo R, Sabbioni S, Magri E, Pedriali M, Campiglio M, Menard S, Palazzo JP, Rosenberg A, Musiani P, Volinia S, Nenci I, Calin GA, Querzoli $\mathrm{P}$, Negrini $\mathrm{M}$ and Croce CM: MicroRNA gene expression deregulation in human breast cancer. Cancer Res 65: 70657070, 2005.

66 Du WW, Fang L, Li M, Yang X, Liang Y, Peng C, Qian W, O'Malley YQ, Askeland RW, Sugg SL, Qian J, Lin J, Jiang Z, Yee AJ, Sefton M, Deng Z, Shan SW, Wang CH and Yang BB: MicroRNA miR-24 enhances tumor invasion and metastasis by targeting PTPN9 and PTPRF9 to promote EGF signaling. J Cell Sci 126: 1440-1453, 2013.

67 Tonks NK: Protein tyrosine phosphatases: from genes, to function, to disease. Nat Rev Mol Cell Biol 7: 833-846, 2006.

68 Yuan T, Wang Y, Zhao ZJ and Gu H: Protein-tyrosine phosphatase PTPN9 negatively regulates ErbB2 and epidermal growth factor receptor signaling in breast cancer cells. J Biol Chem 285: 14861-14870, 2010.

69 Parvani JG, Taylor MA and Schiemann WP: Noncanonical TGF $\beta$ signaling during mammary tumorigenesis. J Mammary Gland Biol Neoplasia 16: 127-146, 2011. 
70 Taylor MA, Sossey-Alaoui K, Thompson CL, Danielpour D and Schiemann WP: TGF $\beta$ up-regulates miR-181a expression to promote breast cancer metastasis. J Clin Invest 123: 150-163, 2013.

71 Nagaprashanta LD, Vatsayan R, Leisani PC, Awasthi S and Singhal SS: The sensors and regulators of cell-matrix surveillance in anoikis resistance of tumors. Int J Cancer 128: 743-752, 2011.

72 Karnoub AE, Dash AB, Vo AP, Sullivan A, Brooks MW, Bell GW, Richardson AL, Polyak K, Tubo R and Weinberg RA: Mesenchymal stem cells within tumor stroma promote breast cancer metastasis. Nature 449: 557-563, 2007.

73 Shi Y, Du L, Lin L and Wang Y: Tumour-associated mesenchymal stem/stromal cells: emerging therapeutic targets. Nat Rev Drug Discov 16: 35-52, 2017.

74 Cuiffo BG, Campagne A, Bell GW, Lembo A, Orso F, Lien EC, Bhasin MK, Raimo M, Hanson SE, Marusyk A, El-Ashry D, Hematti P, Polyak K, Mechta-Grigoriou F, Mariani O, Volinia S, Vincent-Salomon A, Taverna D and Karnoub AE: MSCregulated microRNAs converge on the transcription factor FOXP2 and promote breast cancer metastasis. Cell Stem Cell 15: 762-774, 2014.

75 Fisher SE and Scharff C: FOXP2 as a molecular window into speech and language. Trends Genet 25: 166-177, 2009.

76 Liu Y, Lai L, Chen Q, Song Y, Xu S, Ma F, Wang X, Wang j, $\mathrm{Yu} \mathrm{H}, \mathrm{Cao} \mathrm{X}$ and Wang Q: MicroRNA-494 is required for the accumulation and functions of tumor-expanded myeloid-derived suppressor cells via targeting PTEN. J Immunol 188: 55005510, 2012.

77 Gabrilovich DI and Nagaraj S: Myeloid-derived suppressor cells as regulators of the immune system. Nat Rev Immunol 9: 162-174, 2009.

78 Chabottaux V and Noel A: Breast cancer progression: insights into multifaceted matrix metalloproteinases. Clin Exp Metastasis 24: 647-656, 2007.

79 Zhang L, Zhang S, Yao J, Lowery FJ, Zhang Q, Huang WC, Li $\mathrm{P}$, Li M, Wang X, Zhang C, Wang H, Ellis K, Cheerathodi M, McCarty JH, Palmieri D, Saunus J, Lakhani S, Huang S, Sahin AA, Aldsape LD, Steeg PS and Yu D: Microenvironmentinduced PTEN loss by exosomal microRNA primes brain metastasis outgrowth. Nature 527: 100-104, 2015.

80 Conti I and Rollins BJ: CCL2 (monocyte chemoattractant protein-1) and cancer. Sem Cancer Biol 14: 149-154, 2004.

81 Qian BZ, Li Y, Zhang H, Kitamura T, Zhang J, Campion LR, Kaiser EA, Snyder LA and Pollard JW: CCL2 recruits inflammatory monocytes to facilitate breast-tumor metastasis. Nature 475: 222-225, 2011.

82 Bonapace L, Coissieux MM, Wyckoff J, Mertz KD, Varga Z, Junt $\mathrm{T}$ and Bentires-Alj M: Cessation of CCL2 inhibition accelerates breast cancer metastasis by promoting angiogenesis. Nature 515: 130-133, 2014.

83 Zhou W, Fong MY, Min Y, Somlo G, Liu L, Palomares MR, Yu Y, Chow A, O'Connor ST, Chin AR, Yen Y, Wang Y, Marcusson EG, Chu P, Wu J, Wu X, Li AX, Li Z, Gao H, Ren X, Boldin MP, Lin PC and Wang SE: Cancer-secreted miR-105 destroys vascular endothelial barriers to promote metastasis. Cancer Cell 25: 501-515, 2014.

84 Gonzalez-Mariscal L, Tapia R and Chamorro D: Cross-talk of tight junction components with signaling pathways. Biochim Biophys Acta 1778: 729-756, 2008.
85 Fong MY, Zhou W, Liu L, Alontaga AY, Chandra M, Ashby J, Chow A, O'Connor ST, Li S, Chin AR, Somlo G, Palomares M, Li Z, Tremblay JR, Tsuyada A, Sun G, Reid MA, Wu X, Swiderski P, Ren X, Shi Y, Kong M, Zhong W, Chen Y and Wang SE: Breast-cancer secreted miR-122 reprograms glucose metabolism in premetastatic niche to promote metastasis. Nat Cell Biol 17: 183-194, 2015

86 Gao X, Wang H, Yang JJ, Liu X and Liu ZR: Pyruvate kinase M2 regulates gene transcription by acting as a protein kinase. Mol Cell 45: 598-609, 2012.

87 Luo W, Hu H, Chang R, Zhong J, Knabel M, O’Meally R, Cole RN, Pandey A and Semenza GL: Pyruvate kinase M2 is a PHD3-stimulated coactivator for hypoxia-inducible factor 1 . Cell 145: 732-744, 2011.

88 Peinado H, Lavotshkin S and Lyden D: The secreted factors responsible for pre-metastatic niche formation: old sayings and new thoughts. Sem Cancer Biol 21: 139-146, 2011.

89 Wu X, Somlo G, Yu Y, Palomares MR, Li AX, Zhou W, Chow A, Yen Y, Ross JJ, Gao H, Wang J, Yuan YC, Frankel P, Li S, Ashing-Giwa KT, Sun G, Wang Y, Smith R, Robinson K, Ren $X$ and Wang SE: De novo sequencing of circulating miRNAs identifies novel markers predicting clinical outcome of locally advanced breast cancer. J Transl Med 10: 42, 2012.

90 Lin EY and Pollard JW: Tumor-associated macrophages press the angiogenic switch in breast cancer. Cancer Res 67: 50645066, 2007.

91 Luo Y, Zhou H, Krueger J, Kaplan C, Lee SH, Dolman C, Markowitz D, Wu W, Liu C, Reisfeld RA and Xiang R: Targeting tumor-associated macrophages as a novel strategy against breast cancer. J Clin Invest 116: 2132-2144, 2006.

92 Yang M, Chen J, Su F, Yu B, Su F, Lin L, Liu Y, Huang JD and Song E: Microvesicles secreted by macrophages shuttle invasion-potentiating microRNAs into breast cancer cells. Mol Cancer 10: 117, 2011.

93 Vanpoucke G, Goossens S, De Crane B, Gilbert B, van Roy F and Berx G: GATA-4 and MEF2C transcription factors control the tissue-specific expression of alphaT-catenin gene CTNNA3. Nucleic Acids Res 32: 4155-4165, 2004.

94 Xu X, Zhang Y, Jasper J, Lykken E, Alexander PB, Markowitz GJ, McDonnell DP, Li QJ and Wang XF: MiR-148a functions to suppress metastasis and serves as a prognostic indicator in triple-negative breast cancer. Oncotarget 7: 20381-20394, 2016.

95 Reya $\mathrm{T}$ and Clevers $\mathrm{H}$ : Wnt signaling in stem cells and cancer. Wnt signalling in stem cells and cancer. Nature 434: 843-850, 2005.

96 Malanchi I and Huelsken J: Cancer stem cells: never Wnt away from niche. Current Opin Oncol 21: 41-46, 2009.

97 Glinka Y, Mohammed N, Subramaniam V, Jothy S and Proudhomme GJ: Neuropilin-1 is expressed by breast cancer stem-like cells and is linked to NF- $\mathrm{kB}$ activation and tumor sphere formation. Biochem Biophys Res Commun 425: 775-780, 2012.

98 Ellis LM: The role of neuropilins in cancer. Cancer Ther 5: 1099-1107, 2006.

99 Cimino D, De Pitta C, Orso F, Zampini M, Casara S, Penna E, Quaglino E, Forni M, Damasco C, Pinatel E, Ponzone R, Romualdi C, Brisken C, De Bertoli M, Biglia N, Provero P, Lanfranchi $\mathrm{G}$ and Taverna D: miR148b is a major coordinator of breast cancer progression in a relapse-associated microRNA signature by targeting ITGA5, ROCK1, PIK3CA, NRAS and CSF1. FASEB J 27: 1223-1235, 2013. 
100 Mierke CT, Frey B, Fellner M, Herrmann M and Fabry B: Integrin $\alpha 5 \beta 1$ facilitates cancer cell invasion through enhanced contractile forces. J Cell Sci 124: 369-383, 2011.

101 Desgrosellier JS and Cheresh DA: Integrins in cancer: Biological implications and therapeutic opportunities. Nat Rev Cancer 10: 9-22, 2010.

102 Tavazoie SF, Alarcon C, Oskarsson T, Padua D, Wang Q, Bos PD, Gerald WL and Massague J: Endogenous human microRNAs that suppress breast cancer metastasis. Nature 451: 147-152, 2008.

103 Orend $\mathrm{G}$ and Chiquet-Ehrismann R: Tenascin-C induced signaling in cancer. Cancer Lett 244: 143-163, 2006.

104 Hoser M, Baader SL, Bösl MR, Ihmer A, Wegner M and Sock E: Prolonged glial expression of Sox 4 in the CNS leads to architectural cerebellar defects and ataxia. J Neurosci 27: 54955505, 2007.

105 Tiwari N, Tiwari VK, Waldmeier L, Balwierz PJ, Arnold P, Pachov M, Meyer-Schaller N, Schübeler D, van Nimwegen E and Christofori G: Sox4 is a master regulator of epithelialmesenchymal transition by controlling Ezh2 expression and epigenetic reprogramming. Cancer Cell 23: 768-783, 2013.

106 Gao Y, zeng F, Wu JY, Li HY, Fan JJ, Zhang J, Ma DM, Li Y and Song FZ: MiR-335 inhibits migration of breast cancer cells through targeting of oncoprotein c-MET. Tumor Biol 36: 28752883, 2015.

107 Png KJ, Yoshida M, Zhang XH, Shu W, Lee H, Rimmer A, Chan TA, Comen E, Andrade VP, Kim SW, King TA, Hudis CA, Norton L, Hicks J, Massague $\mathrm{J}$ and Tavazoie SF: MicroRNA-335 inhibits tumor reinitiation and is silenced through genetic and epigenetic mechanisms in human breast cancer. Genes Dev 25: 226-231, 2011.

108 Roush S and Slack FJ: The let-7 family of microRNAs. Trends Cell Biol 18: 505-516, 2008.

109 Yu F, Yao H, Zhu P, Zhang X, Pan Q, Gong C, Huang Y, Hu X, Su F, Liebermann J and Song E: Let-7 regulates self renewal and tumorigenicity of breast cancer cells. Cell 131: 1109-1123, 2007.

$110 \mathrm{Hu}$ X, Guo J, Zheng L, Li C, Zheng TM, Tanvi JL, Liang S, Benedetto C, Mitidieri M, Katsaros D, Zhao X, Zhang Y, Huang Q and Zhang L: The heterochronic microRNA let-7 inhibits cell motility by regulating the genes in the actin cytoskeleton pathway in breast cancer. Mol Cancer Res 11: 240250, 2013.

111 Dangi-Garimella S, Yun J, Eves EM, Newman M, Erkeland SJ, Hammond SM, Minn AJ and Rosner MR: Raf kinase inhibitory protein suppresses a metastasis signalling cascade involving LIN28 and let-7. EMBO J 28: 347-358, 2009.

112 Yun J, Frankenberger CA, Kuo WL, Boelens MC, Eves EM, Cheng N, Liang N, Li WH, Ishwaran H, Minn AJ and Rosner MR: Signaling pathway for RKIP and let-7 regulates and predicts metastatic breast cancer. EMBO J 30: 4500-4514, 2011.

113 Itoh-Nakadai A, Hikota R, Muto A, Kometani K, WatanabeMatsui M, sato Y, Kobayashi M, Nakamura A, Miura Y, Yano Y, Tashiro S, Sun J, Ikawa T, Ochiai K, Kurosaki T and Igarashi $\mathrm{K}$ : The transcription repressors Bach2 and Bach1 promote B cell development by repressing the myeloid program. Nat Immunol 15: 1171-1180, 2014.

114 Fusco A and Fedele A: Roles of HMGA proteins in cancer. Nat Rev Cancer 7: 899-910, 2007.
115 Kim SJ, Shin JY, Lee KD, Bae YK, Sung KW, Nam SJ and Chun KH: MicroRNA let-7a suppresses breast cancer cell migration and invasion through down-regulation of C-C chemokine receptor type 7. Breast Cancer Res 14: R14, 2012.

116 Bischoff A, Huck B, Keller B, Strotbek M, Schmid S, Boerries M, Busch H, Müller D and Olayioye MA: miR149 functions as a tumor suppressor by controlling breast epithelial migration and invasion. Cancer Res 74: 5256-5265, 2014.

117 Chan SH, Huang WC, Chang J, Chang KJ, Kuo WH, Wang MY, Lin KY, Uen YH, Hou MF, Lin CM, Jang TH, Tu CW, Lee YR, Lee YH, Tien MT and Wang LH: MicroRNA-149 targets GIT1 to suppress integrin signaling and breast cancer metastasis. Oncogene 33: 4496-4507, 2014.

118 Frische EW and Zwartkruis FJ: Rap1, a mercenary among the Ras-like GTPases. Devel Biol 340: 1-9, 2010.

119 Freeman SA, McLeod SJ, Dukowski J, Austin P, Lee CC, Millen-Martin B, Kubes P, McCafferty DM, Gold MR and Roskelley CD: Preventing the activation or cycling oft he Rap1GTPase alters adhesion and cytoskeletal dynamics and blocks metastatic melanoma extravasation into the lungs. Cancer Res 70: 4590-4601, 2010.

120 Manabe R, Kovalenko M, Webb DJ and Horwitz AR: GIT1 functions in a motile, multi-molecular signaling complex that regulates protrusive activity and cell migration. J Cell Sci 115: 1497-1510, 2002.

121 Zhao J, Tao Y, Zhiu Y, Qin N, Chen C, Tian D and Xu L: MicroRNA-7: a promising new target in cancer therapy. Cancer Cell Int 15: 103, 2015.

$122 \mathrm{Li}$ Q, Zhu F and Chen P: MiR-7 and miR-218 epigenetically control tumor suppressor genes RASSF1A and claudin- 6 by targeting HoxB3 in breast cancer. Biochem Biophys Res Commun 424: 28-33, 2012.

123 Reddy SD, Ohshiro K, Rayala SK and Kumar R: MicroRNA7, a homeobox D10 target, inhibits p21-activated kinase 1 and regulates it functions. Cancer Res 68: 8195-8922, 2008.

124 Kong X, Li G, Yuan Y, He Y, Wu X, Zhang W, Wu Z, Chen T, Wu W, Lobie PE and Zhu T: MicroRNA-7 inhibits epithelialto-mesenchymal transition and metastasis of breast cancer cells via targeting FAK expression. PLoS One 7: e41523, 2012.

125 Okuda H, Xing F, Pandey PR, Sharma S, Watanabe M, Pai SK, Mo YY, Iiizumi-Gairani M, Hirota S, Liu Y, Wu K, Pochampally $\mathrm{R}$ and Watanabe $\mathrm{K}$ : miR-7 suppresses brain metastasis of breast cancer stem-like cells by modulating KLF4. Cancer Res 73: 1434-1444, 2013.

126 Yu N, Huangyang P, Yang X, Han X, Yan R, Jia H, Shang Y and Sun L: microRNA-7 suppresses the invasive potential of breast cancer cells and sensitizes cells to DNA damages by targeting histone methyltransferase SET8. J Biol Chem 288: 19633-19642, 2013.

127 Webster RJ, Giles KM, Price KJ, Zhang PM, Mattick JS and Leedman PJ: Regulation of epidermal growth factor receptor signaling in human cancer cells by microRNA-7. J Biol Chem 284: 5731-5741, 2009.

128 Lark AL, Livasy CA, Dressler L, Moore DT, Millikan R, Geradts J, Iacocca M, Cowan D, Little D, Craven RJ and Chance W: High focal adhesion kinase expression in invasive breast carcinoma is associated with an aggressive phenotype. Mod Pathol 18: 1289-1294, 2005.

129 Kumar R, Guruaj AE and Barnes CJ: p21-activated kinases in cancer. Nat Rev Cancer 6: 459-471, 2006. 
130 Yu F, Li J, Fu J, Ray S, Huang S, Zheng H and Ai W: Kruppellike factor 4 (KLF4) is required for maintainance of breast cancer stem cells and for cell migration and invasion. Oncogene 30: 2161-2172, 2011.

131 Pandya AY, Talley LI, Frost AR, Fitzgerald TJ, Trivedi V, Chakravarthy M, Chieng DC, Grizzle WE, Engler JA, Krontiras H, Bland KI, LoBuglio AF, Lobo-Ruppert SM and Ruppert JM: Nuclear localization of KLF4 is associated with an aggressive phenotype in early-stage breast cancer. Clin Cancer Res 10: 2709-2719, 2004.

132 Chou J, Lin JH, Brenot A, Kim JW, Provot S and Werb Z: GATA3 suppresses metastasis and modulates the tumor microenvironment by regulating microRNA-29b expression. Nat Cell Biol 15: 201-213, 2013.

133 Asselin-Labat ML, Sutherland KD, Barker H, Thomas R, Shackleton M, Forrest NC, Hartley L, Robb L, Grosveld F, van der Weens, Lindeman GJ and Visvader IF: Gata-3 is an essentiell regulator of mammary-gland morphogenesis and luminal dofferentiation. Nat Cell Biol 9: 201-209, 2007.

134 Chou J, Provot S and Werb Z: GATA3 in development and cancer: cells GATA have it. J Cell Physiol 222: 42-49, 2010.

135 Yoon NK, Maresh EL, Shen D, Elshimali Y, Apple S, Horvath S, Mah, Bose S, Chia D, Chang HR and Goodglick L: Higher levels of GATA3 predict better survival in women with breast cancer. Hum Pathol 41: 1794-1801, 2010.

136 Mehra R, Varambally S, Ding L, Hen R, Sabel MS, Ghosh D, Chinnaiyan AM and Kleer CG: Identification of GATA3 as a breast cancer prognostic marker by global gene expression and meta-analysis. Cancer Res 65: 11259-11264, 2005.

137 Png KJ, Halberg N, Yoshida M and Tavazoie SF: A microRNA regulon that mediates endothelial recruitment and metastasis by cancer cells. Nature 481: 190-194, 2011.

138 Zhang Y, Yang P, Sun T, Li D, Xu X, Rui Y, Li C, Chong M, Ibrahim T, Mercatali L, Amadori D, Lu X, Xie D, Li DQ and Wang XF: miR-126 and mir-126* repress recruitment of mesenchymal stem cells and inflammatory monocytes to inhibit breast cancer metastasis. Nat Cell Biol 15: 284-294, 2013.

139 Jones JI and Clemens DR: Insulin-like growth factors and their binding proteins: biological actions. Endocr Rev 16: 3-34, 1995.

140 Sather S, Kenyon KD, Lefkowitz JB, Liang X, Varnum BC, Henson PM and Graham DK: A soluble form of the Mer receptor kinase inhibits macrophage clearance of apoptotic cells and platelet aggregation. Blood 109: 1026-1033, 2007.

141 Garner K, Hunt AN, Koster G, Somerharju P, Groves E, Li M, Raghu P, Holic R and Cockcroft S: Phosphatidylinositol transfer protein, cytoplasmic 1 (PITPNC1) binds and transfers phosphatidic acid. J Biol Chem 287: 32263-32276, 2012.

142 Marchesi F, Monti P, Leone BE, Zerbi A, Vecchi A, Piemonti L, Montovani A and Allavena P: Increased survival, proliferation, and migration in metastatic human pancreatic tumor cells expressing functional CXCR4. Cancer Res 64: 8420-8427, 2004.

143 Xu D, Takeshita F, Hino Y, Fukunaga S, Kudo Y, Tamaki A, Matsunaga J, Takahashi RU, Takata T, Shimatomoto A, Ochiya $\mathrm{T}$ and Tahara $\mathrm{H}$ : miR-22 represses cancer progression by inducing cellular sensecence. J Cell Biol 193: 409-424, 2011.

144 Yu F, Deng H, Yao H, Liu Q, Su F and Song E: Mir-30 reduction maintains self-renewal and inhibits apoptosis in breast tumor-initiating cells. Oncogene 29: 4194-4204, 2010.
145 Krzeszinski JY, Wie W, Huynh H, Yin Z, Wang X, Chang TC, Xie J, He L, Mangala LS, Lopez-Berestein G, Sood AK, Mendell JT and Wan Y: miR-34a blocks osteporosis and bone metastasis by inhibiting osteoclastogenesis and Tgif2. Nature 512: 431-435, 2014.

146 Li G, Yao L, Zhang J, Li X, Dang S, Zeng K, Zhou Y and Gao F: Tumor-suppressive microRNA-34a inhibits breast cancer cell migration and invasion via targeting oncogenic TPD52. Tumor Biol 37: 7481-7491, 2016.

147 Mittal MK, Singh K, Misra S and Chauduri G: SLUG-induced elevation of D1 cyclin in breast cancer through the inhibition of its ubiquitination. J Biol Chem 286: 469-479, 2011.

148 Liang YJ, Wang QY, Zhou CX, Yin QQ, He M, Yu XT, Cao DX, Chen GQ, He JR and Zhao Q: MiR-124 targets Slug to regulated epithelial-mesenchymal transition and metastasis of breast cancer. Carcinogenesis 34: 713-722, 2013.

149 Baldus DE, Engelmann K and Hanisch FG: MUC1 and the MUCs: a family of human mucins with impact in cancer biology. Crit Rev Clin Lab Sci 41: 189-231, 2004.

150 Sachdeva M and Mo YY: MicroRNA-145 suppresses cell invasion and metastasis by directly targeting mucin 1 . Cancer Res 70: 378-387, 2010.

151 Sidenius N and Blasi F: The urokinase plasminogen activator system in cancer: recent advances and implications for prognosis and therapy. Cancer Metastasis Rev 22: 205-222, 2003.

152 Li XF, Yan PJ and Shao ZM: Down-regulation of miR-193b contributes to enhance urokinase-type plasminogen activator (uPA) expression and tumor progression and invasion in human breast cancer. Oncogene 28: 3937-3948, 2009

$153 \mathrm{Wu} \mathrm{H}$, Zhu S and Mo YY: Suppression of cell growth and invasion by miR-205 in breast cancer. Cell Res 19: 439-448, 2009.

154 Yu J, Wang JG, Zhang L, Yang HP, Wang L, Ding D, Chen Q, Yang WL, Ren KH, Zhou DM, Zou Q, Jin YT and Liu XP: MicroRNA-320a inhibits breast cancer metastasis by targeting metadherin. Oncotarget 7: 38612-38625, 2016.

155 Brown DM and Ruoslahti E: metadherin, a cell surface protein in breast tumors that mediates lung metastasis. Cancer Cell 5: 365-374, 2004.

156 Pan Y, Jiao G, Wang C, Yang J and Yang W: MicroRNA-421 inhibits breast cancer metastasis by targeting metastasis associated 1. Biomed Pharmacother 83: 1398-1406, 2016.

157 Da-Qiang Li, Pakala SB, Nair SS, Eswaran J and Kumar R: Metastasis associated protein 1/nucleosome remodeling and histone deacetylase complex in cancer. Cancer Res 72: 387-394, 2012.

158 Dyxhoorn DM: MicroRNAs and metastasis. Little RNAs go a long way. Cancer Res 70: 6401-6406, 2010.

159 Park SM, Gaur AB, Lengyel E and Peter ME: The miR-200 family determines the epithelial phenotype of cancer cells by targeting the E-cadherin repressors ZEB1 and ZEB2. Genes Dev 22: 894-907, 2008.

160 Le MT, Hamar P, Guo C, Basar E, Perdigao-Henriques R, Balaj $\mathrm{L}$ and Lieberman J: miR-200 containing extracellular vesicles promote breast cancer cell metastasis. J Clin Invest 124: 5109$5128,2014$.

161 Korpal M, Ell BJ, Buffa FM, Ibrahim T, Blanco MA, CecilaTerrassa T, Mercatali L, Khan Z, Goodarzi H, Hua Y, Wie Y, $\mathrm{Hu}$ G, Garcia BA, Ragoussis J, Amadori D, Harris AL and 
Kang Y: Direct targeting of Sec23a by miR-200s influences cancer cell secretome and promotes metastatic colonization. Nature Med 17: 1101-1108, 2011.

162 Townley AK, Feng Y, Schmidt K, Carter DA, Porter R, Verkade $\mathrm{P}$ and Stephens DJ: Efficient coupling of sec23-sec24 to sec13$\sec 31$ drives COPII-dependent collagen secretion and is essential for normal craniofacial development. J Cell Sci 15 : 3025-3034, 2008.

163 Durai R, Davies M, Yang W, Yang SY, Seifalaian A, Goldspink $\mathrm{G}$ and Winslet M: Biology of insulin-like growth factor binding protein-4 and its role in cancer (review). Int J Oncol 28: 13171325, 2006.

164 Igarashi T, Tajiri Y, Sakurai M, Sato Em Li D, Mukai K, Suematsu M, Fukui E, Yoshizawa $M$ and Matsumoto $H$ : Tubulointerstitial nephritis antigen-like 1 is expressed in extraembryonic tissues and interacts with laminin 1 in the Reichert membrane at postimplantation in the mouse. Biol Reprod 81: 948-955, 2009.

165 Wang Y, Klijn JG, Zhang Y, Sieuwerts AM, Look MP, Yang F, Talantov D, Timmermans M, Meijer van-Gelder ME, Yu J, Jatkoe T, Berns EM, Atkins D and Foekens JA: Gene expression profiles to predict distant metastasis of lymph-node negative primary breast cancer. Lancet 365: 671-679, 2005.

166 Sossey-Alaoui K, Bialkowska K and Plow EF: The miR200 family of microRNAs regulates WAVE3-dependent cancer cell invasion. J Biol Chem 284: 33019-33029, 2009.

167 Sossey-Alaoui K, Li X and Cowell JK: c-Abl mediated phosphorylation of WAVE3 is required for lamellopodia formation and cell migration. J Biol Chem 282: 26527-26565, 2007.

168 Tang X, Hou Y, Yang G, Wang X, Tang S, Du YE, Yang L, Yu T, Zhang H, Zhou M, Wen S, Xu L and Liu M: Stromal miR-200s contribute to breast cancer cell invasion through CAF activation and ECM remodeling. Cell Death Differ 23: 132-145, 2016.

169 Li Y, Luo H, Liu T, Zacksenhaus E and Ben-David Y: The ets transcription factor Fli-1 in development cancer and disease. Oncogene 34: 2022-2031, 2015.

170 Zhang Y, Babin J, Feldhaus AL, Singh H, Sharp PA and Bina M: HTF4: a new human helix-loop-helix protein. Nucleic Acids Res 19: 4555, 1991.

171 Gravgard KH, Lyng MB, Laenkholm AV, Sokilde R, Nielsen BS, Litman T and Ditzel HJ: The miRNA-200 family and miR9 exhibit differential expression in primary versus corresponding metastatic tissue in breast cancer. Breast Cancer Res Treat 134: 207-217, 2012.

172 Paterson EL, Kazenwadel J, Bert AG, Khew-Goodall Y, Ruszkiewiecz A and Goodall GJ: Down-regulation of the miR200 family at the invasive front of colorectal cancers with degraded basement membrane indicates EMT is involved in cancer progression. Neoplasia 15: 180-191, 2013.

173 Wei F, Cao C, Xu X and Wang J: Diverse functions of miR-373 in cancer. J Transl Med 13: 162, 2015.

174 Huang Q, Gumireddy K, Schier M, le Sage C, Nagel R, Nair S, Egan DA, Li A, Huang G, Klein-Szanto AJ, Gimotty PA, Katsaros D, Coukos G, Zhang L, Pure E and Agami R: The microRNAs miR-373 and miR-520c promote invasion and metastasis. Nat Cell Biol 10: 202-210, 2008.

175 Chen D, Dang BL, Huang JZ, Chen M, Wu D, Xu ML, Li R and Yan GR: MiR-373 drives epithelial-to-mesenchymal transition and metastasis via the miR-373-TXNIP-HIF1 $\alpha$
TWIST signaling axis in breast cancer. Oncotarget 6: 3270132712, 2015.

176 Keklikoglou I, Koerner C, Schmidt C, Zhang JD, Heckmann D, Shavinskaya A, Allgayer H, Gückel B, Fehm T, Schneeweiss A, Sahin O, Wiemann S and Tschulena U: MicroRNA-520/373 family functions as a tumor suppressor in estrogen receptor negative breast cancer by targeting NFKB and TGF- $\beta$ signaling pathways. Oncogene 31: 4150-4163, 2012.

177 Braun S, Vogl FD, Naume B, Jani W, Osborne MP, Combes RC, Schlimok G, Diel IJ, Gerber B, Gebauer G, Pierga JY, Marth C, Oruzio, Wiedswang G, Solomayer EF, Kundt G, Strobl B, Fehm T, Wong GY, Bliss J, Vincent-Salomon A and Pantel K: A pooled analysis of bone marrow micrometastasis in breast cancer. NEJM 353: 793-802, 2005.

178 Pantel K, Brakenhoff RH and Brandt B: Detection, clinical relevance and specific biological properties of disseminating tumor cells. Nat Rev Cancer 8: 329-340, 2008.

179 Garzon R, Marucci G and Croce CM: Targeting microRNAs in cancer: rationale, strategies and challenges. Nat Rev Drug Discov 9: 775-789, 2010.

180 Broderick JA and Zamore PD: MicroRNA therapeutics. Gene Ther 18: 1104-1110, 2011.

181 Ling H, Fabbri M and Calin GA: MicroRNAs and other noncoding RNAs as targets for anticancer drug development. Nat Drug Discov 12: 847-865, 2013.

$182 \mathrm{Li} \mathrm{Z}$ and Rana TM: Therapeutic targeting of microRNAs: current status and future challenges. Nat Rev Drug Discov 13: 622-638, 2014.

183 Matsui M and Corey DR: Non-coding RNAs as drug targets. Nat Rev Drug Discov 16: 167-179, 2017.

184 Jung S, Lee SH, Mok H, Chung HJ and Park TG: Gene silencing efficiency of siRNA-PEG conjugates: effect of PEGylation site and PEG molecular weight. J Control Release 144: 306-313, 2010.

185 Mui BL, Tam YK, Jayaraman M, Ansell SM, Du X, Tam YY, Lin PJ, Chen S, Narayanannair JK, Rajeev KG, Manoharan M, Akinc A, Maier MA, Cullis P, Madden TD and Hope MJ: Influence of polyethylene glycol lipid desorption rates on pharmacokinetics and pharmacodynamics of siRNA lipid nanoparticles. Mol Ther Nucleic Acids 2: e139, 2013.

186 Malek A, Merkel O, Fink L, Czubayko F, Kissel T and Aigner A: In vivo pharmacokinetics, tissue distribution and underlying mechanisms of various PEI(-PEG)/siRNA complexes. Toxicol Appl Pharmacol 236: 97-108, 2009.

187 Wang AZ, Langer R and Farokhzad OC: Nanoparticle delivery of cancer drugs. Annu Rev Med 63: 185-198, 2012.

188 De Paula D, Bentley MV and Mahato RI: Hydrophobization and bioconjugation for enhanced siRNA delivery and targeting. RNA 13: 431-456, 2007.

189 Basha G, Novobrantseva TI, Rosin N, Tam YYC, Hafez IM, Wong MK, Sugo T, Ruda VM, Qin J, Klebanov B, Ciufolini M, Akinc A, Tam YK, Hope MJ and Cullis PR: Influence of cationic lipid composition on gene silencing properties of lipid nanoparticle formulations of siRNA in antigen-presenting cells. Mol Ther 19: 2186-2200, 2011.

190 Zimmermann TS, Lee AC, Akinc A, Bramlage B, Bumcrot D, Fedoruk MN, Harborth J, Heyes JA, Jeffs LB, John M, Judge AD, Lam K, McClintock K, Nechev LV, Palmer LR, Racie T, Rohl I, Seiffert S, Shanmugam S, Sood V, Soutschek J, Toudjarska I, Wheat AJ, Yaworski E, Zedalis W, Koteliansky 
V, Manoharan M, Vornlocher HP and MacLachlan I: RNAimediated gene silencing in non-human primates. Nature 441: 111-114, 2006.

191 Wittrup A and Lieberman J: Knocking down disease: A progress report on siRNA therapeutics. Nat Rev Genet 16: 543$552,2015$.

192 Rozema DB, Lewis DL, Wakefield DH, Wong SC, Klein JJ, Roesch PL, Bertin SL, Reppen TW, Chu Q, Blokhin AV, Hagstrom JE and Wolff JA: Dynamic PolyConjugates for targeted in vivo delivery of siRNA to hepatocytes. P Natl Acad Sci USA 104: 12982-12987, 2007.

193 Wong SC, Klein JJ, Hamilton HL, Chu Q, Frey CL, Trubetskoy VS, Hegge J, Wakefield D, Rozema DB and Lewis DL: Coinjection of a targeted, reversibly masked endosomolytic polymer dramatically improves the efficacy of cholesterolconjugated small interfering RNAs in vivo. Nucleic Acid Ther 22: 380-390, 2012.

194 Smith D, Schuller V, Engst C, Radler J and Liedl T: Nucleic acid nanostructures for biomedical applications. Nanomedicine (Lond) 8: 105-121, 2013.

195 Lee H, Lytton-Jean AK, Chen Y, Love KT, Park AI, Karagiannis ED, Sehgal A, Querbes W, Zurenko CS, Jayaraman M, Peng CG, Charisse K, Borodovsky A, Manoharan M, Donahoe JS, Truelove J, Nahrendorf M, Langer $\mathrm{R}$ and Anderson DG: Molecularly self-assembled nucleic acid nanoparticles for targeted in vivo siRNA delivery. Nat Nanotechnol 7: 389-393, 2012.

196 Kanasty R, Dorkin JR, Vegas A, and Anderson D: Delivery materials for siRNA therapeutics. Nat Mater 12: 967-977, 2013.

197 Spiess M: The asialoglycoprotein receptor - a model for endocytic transport receptors. Biochemistry-Us 29: 1009-1018, 1990.

198 Nair JK, Willoughby JLS, Chan A, Charisse K, Alam MR, Wang QF, Hoekstra M, Kandasamy P, Kel'in AV, Milstein S, Taneja N, O'Shea J, Shaikh S, Zhang LG, van der Sluis RJ, Jung ME, Akinc A, Hutabarat R, Kuchimanchi S, Fitzgerald K, Zimmermann T, van Berkel TJC, Maier MA, Rajeev KG and Manoharan M: Multivalent $\mathrm{N}$-acetylgalactosamine-conjugated sirna localizes in hepatocytes and elicits robust RNAi-mediated gene silencing. J Am Chem Soc 136: 16958-16961, 2014.

199 Ozcan G, Ozpolat B, Coleman RL, Sood AK and LopezBerestein G: Preclinical and clinical development of siRNAbased therapeutics. Adv Drug Deliv Rev 87: 108-119, 2015.

200 Cuellar TL, Barnes D, Nelson C, Tanguay J, Yu SF, Wen XH, Scales SJ, Gesch J, Davis D, Smith AV, Leake D, Vandlen R and Siebel CW: Systematic evaluation of antibody-mediated siRNA delivery using an industrial platform of THIOMABsiRNA conjugates. Nucleic Acids Res 43: 1189-1203, 2015.

201 Schiffelers RM, Ansari A, Xu J, Zhou Q, Tang Q, Storm G, Molema G, Lu PY, Scaria PV and Woodle MC: Cancer siRNA therapy by tumor selective delivery with ligand-targeted sterically stabilized nanoparticle. Nucleic Acids Res 32: e149, 2004.

202 Yoshizawa T, Hattori Y, Hakoshima M, Koga K and Maitani Y: Folate-linked lipid-based nanoparticles for synthetic siRNA delivery in KB tumor xenografts. Eur J Pharm Biopharm 70: 718-725, 2008.

203 Farokhzad OC, Jon S, Khademhosseini A, Tran TN, Lavan DA and Langer R: Nanoparticle-aptamer bioconjugates: a new approach for targeting prostate cancer cells. Cancer Res 64: 7668-7672, 2004.
204 Chu TC, Twu KY, Ellington AD and Levy M: Aptamer mediated siRNA delivery. Nucleic Acids Res 34: e73, 2006.

205 Diao Y, Liu J, Ma Y, Su M, Zhang H and Hao X: A specific aptamer-cell penetrating peptides complex delivered siRNA efficiently and suppressed prostate tumor growth in vivo. Cancer Biol Ther 17: 498-506, 2016.

206 Baumer N, Appel N, Terheyden L, Buchholz F, Rossig C, Muller-Tidow C, Berdel WE and Baumer S: Antibody-coupled siRNA as an efficient method for in vivo mRNA knockdown. Nat Protoc 11: 22-36, 2016.

207 Schneider B, Grote M, John M, Haas A, Bramlage B, Ickenstein LM, Jahn-Hofmann K, Bauss F, Cheng W, Croasdale R, Daub K, Dill S, Hoffmann E, Lau W, Burtscher H, Ludtke JL, Metz S, Mundigl O, Neal ZC, Scheuer W, Stracke J, Herweijer $\mathrm{H}$ and Brinkmann $\mathrm{U}$ : Targeted siRNA delivery and mRNA knockdown mediated by bispecific digoxigenin-binding antibodies. Mol Ther Nucleic Acids 1: e46, 2012.

208 Song EW, Zhu PC, Lee SK, Chowdhury D, Kussman S, Dykxhoorn DM, Feng Y, Palliser D, Weiner DB, Shankar P, Marasco WA and Lieberman J: Antibody mediated in vivo delivery of small interfering RNAs via cell-surface receptors. Nat Biotechnol 23: 709-717, 2005.

209 Juliano RL, Ming X and Nakagawa O: Cellular uptake and intracellular trafficking of antisense and siRNA oligonucleotides. Bioconjug Chem 23: 147-157, 2012.

210 Sahay G, Querbes W, Alabi C, Eltoukhy A, Sarkar S, Zurenko C, Karagiannis E, Love K, Chen D, Zoncu R, Buganim Y, Schroeder A, Langer R and Anderson DG: Efficiency of siRNA delivery by lipid nanoparticles is limited by endocytic recycling. Nat Biotechnol 31: 653-658, 2013.

211 Derossi D, Joliot AH, Chassaing G and Prochiantz A: The third helix of the Antennapedia homeodomain translocates through biological membranes. J Biol Chem 269: 10444-10450, 1994.

212 Copolovici DM, Langel K, Eriste E and Langel U: Cellpenetrating peptides: design, synthesis, and applications. ACS Nano 8: 1972-1994, 2014.

213 Thoren PE, Persson D, Isakson P, Goksor M, Onfelt A and Norden B: Uptake of analogs of penetratin, Tat(48-60) and oligoarginine in live cells. Biochem Biophys Res Commun 307: 100-107, 2003.

214 Haas AK, Maisel D, Adelmann J, von Schwerin C, Kahnt I and Brinkmann U: Human-protein-derived peptides for intracellular delivery of biomolecules. Biochem J 442: 583-593, 2012.

215 Boussif O, Zanta MA and Behr JP: Optimized galenics improve in vitro gene transfer with cationic molecules up to 1000 -fold. Gene Ther 3: 1074-1080, 1996.

216 Zorko M and Langel U: Cell-penetrating peptides: mechanism and kinetics of cargo delivery. Adv Drug Deliver Rev 57: 529$545,2005$. 